\title{
Modelling the size distribution of aggregated volcanic ash and implications for operational atmospheric dispersion modelling
}

\author{
Frances Beckett ${ }^{1}$, Eduardo Rossi ${ }^{2}$, Benjamin Devenish ${ }^{1}$, Claire Witham $^{1}$, and Costanza Bonadonna ${ }^{2}$ \\ ${ }^{1}$ Met Office, Exeter, UK \\ ${ }^{2}$ University of Geneva, Switzerland
}

Correspondence: Frances Beckett (frances.beckett@metoffice.gov.uk)

\begin{abstract}
.
We have developed an aggregation scheme for use with the Lagrangian atmospheric transport and dispersion model NAME, which is used by the London Volcanic Ash Advisory Centre (VAAC) to provide advice and guidance on the location of volcanic ash clouds to the aviation industry. The aggregation scheme uses the fixed pivot technique to solve the Smoluchowski coagulation equations to simulate aggregation processes in an eruption column. This represents the first attempt at modelling explicitly the change in the grain size distribution (GSD) of the ash due to aggregation in a model which is used for operational response. To understand the sensitivity of the output aggregated grain size distribution (AGSD) to the model parameters we conducted a simple parametric study and scaling analysis. We find that the modelled AGSD is sensitive to the density distribution and grain size distribution assigned to the non-aggregated ash at the source. Our ability to accurately forecast the long-range transport of volcanic ash clouds is, therefore, still limited by real-time information on the physical characteristics of the ash. We assess the impact of using the AGSD on model simulations of the Eyjafjallajökull 2010 ash cloud, and consider the implications for operational forecasting. Using the time-evolving AGSD at the top of the eruption column to initialise dispersion model simulations had little impact on the modelled extent and mass loadings in the distal ash cloud. Our aggregation scheme does not account for the density of the aggregates; however, if we assume that the aggregates have the same density of single grains of equivalent size the modelled extent of the Eyjafjallajökull ash cloud with high concentrations of ash, significant for aviation, is reduced by $\sim 3 \%$. If we assume that the aggregates have a lower density $\left(500 \mathrm{~kg} \mathrm{~m}^{-3}\right)$ than the single grains of which they are composed and make-up $75 \%$ of the mass in the ash cloud the extent is 1.2 times larger.
\end{abstract}




\section{Introduction}

In volcanic plumes ash can aggregate together, bound by hydro-bonds and electrostatic forces. Aggregates typically have diameters $>63 \mu \mathrm{m}$ (Brown et al., 2012) and their fall velocity differs to that of the single grains of which they are composed (Lane et al., 1993; James et al., 2003; Taddeucci et al., 2011; Bagheri et al., 2016). Neglecting aggregation in atmospheric dispersion models could, therefore, lead to errors when modelling the rate of removal of ash from the atmosphere, and consequently inaccurate forecasts of the concentration and extent of volcanic ash clouds used by civil aviation for hazard assessment (e.g. Folch et al., 2010; Mastin et al., 2013; Beckett et al., 2015; Mastin et al., 2016).

The theoretical description of aggregation is still far from fully understood, mostly due to the complexity of particle-particle interactions within a highly turbulent fluid. There have been several attempts to provide an empirical description of the aggregated grain size distribution (AGSD) by assigning a specific cluster settling velocity to fine ash (Carey and Sigurdsson, 1983) or fitting the distribution used in dispersion models to observations of tephra deposits retrospectively (e.g. Cornell et al., 1983; Bonadonna et al., 2002; Mastin et al., 2013, 2016). Cornell et al. (1983) found that by replacing a fraction of the fine ash with aggregates which had a diameter of $200 \mu \mathrm{m}$ they were able to reproduce the observed dispersal of the Campanian Y-5 ash. Bonadonna et al. (2002) found that the ash deposition from co-pyroclastic density currents and the plume associated with both dome collapses and Vulcanian explosions of the 1995-1999 eruption of Soufrière Hills Volcano (Montserrat) were better described by considering variation in the aggregate size and in the grain-size distribution within individual aggregates. Mastin et al. (2016) determined optimal values for the mean and standard deviation of input AGSDs for ash from the eruptions of Mount St Helen's, Crater Peak (Mount Spurr), Ruapehu and Mount Redoubt using the Ash3d model. They assumed that the aggregates had a Gaussian size distribution and found that for all the eruptions the optimal mean aggregate size was 150-200 $\mu \mathrm{m}$.

There have been only a few attempts to model the process of aggregation explicitly. Veitch and Woods (2001) were the first to represent aggregation in the presence of liquid water in an eruption column using the Smoluchowski Coagulation Equations (SCE) (Smoluchowski, 1916). Textor et al. (2006a, b) introduced a more sophisticated aggregation scheme to the Active Tracer High-resolution Atmospheric Model (ATHAM), also designed to model eruption columns, which included a more robust representation of microphysical processes and simulated the interaction of hydrometeors with volcanic ash. They suggest that wet rather than icy ash has the greatest sticking efficiency and that aggregation is fastest within the eruption column where ash concentrations are high and regions of liquid water exist. More recently microphysical based aggregation schemes which represent multiple collision mechanisms have been introduced to atmospheric dispersion models FALL3D (Costa et al., 2010; Folch et al., 2010) and WRF-Chem (Egan et al., 2019), and an eruption column model, FPLUME (Folch et al., 2016). They all use an approximate solution of the SCE which assumes that aggregates can be described by a fractal geometry and particles aggregate onto a single effective aggregate class defined by a prescribed diameter.

Here we introduce an aggregation scheme coupled to a one-dimensional steady state buoyant plume model which uses a discrete solution of the SCE based on the Fixed Pivot Technique (FPT) (Kumar and Ramkrishna, 1996). As such we are able to model explicitly the evolution of the AGSD with time in the eruption column. We have integrated our aggregation scheme into 
to the Lagrangian atmospheric dispersion model NAME (Numerical Atmospheric Dispersion modelling Environment; Jones et al. (2007). NAME is used operationally by the London Volcanic Ash Advisory Centre (VAAC) to provide real-time forecasts of the expected location and mass loading of ash in the atmosphere (Beckett et al., 2020). In our approach the AGSD at the top of the plume is supplied to NAME to provide a time-varying estimate of the source conditions. This means that aggregation is considered as a key process inside the buoyant plume above the vent but neglected in the atmospheric transport. This choice ensures aggregation is represented where ash concentrations are highest (and aggregation most likely), while also respecting the need for reasonable computation times for an operational system. The manuscript is organised as follows. In Section 2 we present the aggregation scheme. In Section 3 we perform a parametric study to investigate the sensitivity of the modelled AGSD to the internal model parameters and show that the modelled size distribution of the aggregates is sensitive to the initial erupted grain size distribution (GSD) and density of the non-aggregated ash. In Section 4 we present a scale analysis to understand the dependency of the collision kernel on model parameters. In section 5 we assess the impact of using the modelled AGSD on the simulated extent and mass loading of ash in the distal volcanic ash cloud from the eruption of Eyjafjallajökull volcano in 2010, and consider the implications of using an AGSD for operational forecasting. We discuss the results in Section 6, before the conclusions are presented in Section 7.

\section{The Aggregation Scheme}

We use a one-dimensional steady state buoyancy model, where mass, momentum and total energy are derived for a control volume, and time variations are assumed to be negligible (Devenish, 2013, 2016). It combines the effects of moisture (liquid water and water vapour) and the ambient wind, and includes the effects of humidity and phase changes of water, on the growth of the plume. The governing equations are given by:

$\frac{d M_{z}}{d s}=\left(\rho_{a}-\rho_{p}\right) g \pi b^{2}$

75

$\frac{d M_{x, y}}{d s}=-Q_{m} \frac{d U_{i}}{d s}$

$\frac{d H}{d s}=\left(\left(1-q_{v}^{a}\right) c_{p d}+q_{v}^{a} c_{p v}\right) T_{a} \frac{d Q_{m}}{d s}-g Q_{m} \frac{\rho_{a}}{\rho_{p}} \frac{w_{p}}{v_{p}}+\left[L_{v o}-273\left(c_{p v}-c_{p l}\right)\right] \frac{d Q_{l}}{d s}$

$80 \frac{d Q_{t}}{d s}=E q_{v}^{a}$

$$
\frac{d Q_{m}}{d s}=E
$$


where $s$ is the distance along the plume axis, $M_{z}=Q_{m} w_{p}$ is the vertical momentum flux, $M_{i}=\left(u_{p i}-U_{i}\right) Q_{m}$ is the horizontal momentum flux relative to the environment, $H=c_{p p} T Q_{m}$ is the enthalpy flux, $Q_{t}=Q_{m} n_{t}$ is the total moisture flux within the plume, and $Q_{m}=\rho_{p} \pi b^{2} v_{p}$ is the mass flux. The meaning of the symbols used throughout are given in Tables 1 and 2 . The entrainment rate depends on the ambient and plume densities, and when the plume is rising buoyantly is given by:

$E=2 \pi b \sqrt{\rho_{a} \rho_{p}} u_{e}$

where $\rho_{p}$ is the plume density:

$\frac{1}{\rho_{p}}=\frac{n_{g}}{\rho_{g}}+\frac{1-n_{g}-n_{l}}{\rho_{s}}+\frac{n_{l}}{\rho_{l}}$

and $u_{e}$ is the entrainment velocity:

$u_{e}=\left(\left(k_{s}\left|\Delta \mathbf{u}_{\mathbf{s}}\right|\right)^{1.5}+\left(k_{n}\left|\Delta \mathbf{u}_{\mathbf{n}}\right|\right)^{1.5}\right)^{1 / 1.5}$

Here two entrainment mechanisms are considered, one due to velocity differences parallel to the plume axis $\left(\mathbf{u}_{\mathbf{s}}\right)$ and one due to the velocity differences perpendicular $\left(\mathbf{u}_{\mathbf{n}}\right)$ to the plume axis, $k_{s}$ and $k_{n}$ are the entrainment coefficients associated with each respective entrainment mechanism (note $k_{s}$ is given the symbol $\alpha$ and $k_{n}$ the symbol $\beta$ in Devenish (2013)).

As aggregation is controlled by the amount of available water it is essential that we adequately consider the entrainment of water vapour, its condensation threshold, and phase changes from water vapour to ice and liquid water, and vice versa. As such, we have modified the scheme presented by Devenish (2013) to introduce an ice phase. Ice is produced whenever $T<255 K$, the critical temperature in the presence of volcanic ash, following Durant et al. (2008); Costa et al. (2010); Folch et al. (2016). It is assumed that there is no source liquid water or ice flux, given the high temperatures, and that there is no entrainment of ambient liquid water (only water vapour). Liquid water condensate and ice are formed whenever the water vapour mixing ratio $\left(r_{v}\right)$ is larger than the saturation mixing ratio $\left(r_{s}\right)$, which is determined using the Clausius-Clapeyron equation:

$r_{s}=\frac{\varepsilon e_{s}}{p_{d}}$

where $\varepsilon=0.62$ is the molecular mass of water vapour to dry air, $p_{d}$ is the dry ambient pressure and $e_{s}$ is the saturation vapour pressure, which for liquid is given by a modification of Tetens' empirical formula (Emanuel, 1994, pg. 117):

$105 e_{s, l}=6.112 \exp \left(\frac{17.65(T-273.5)}{T-29.65}\right)$

and for ice is given by (Murphy and Koop, 2005, pg. 1558):

$\log e_{s, i c e}=-9.09718\left(\frac{273.16}{T}-1\right)-3.56654 \log \left(\frac{273.16}{T}\right)+0.876793\left(1-\frac{T}{273.16}\right)+\log (610.71)$

The mass fractions of water $\left(n_{l}\right)$ and ice $\left(n_{\text {ice }}\right)$ can then be expressed as:

$n_{l}=\operatorname{Max}\left(0, n_{t, T>255 K}-n_{d} r_{s, l}\right)$ 
$n_{i c e}=\operatorname{Max}\left(0, n_{t, T<255 K}-n_{d} r_{s, i c e}\right)$

where $n_{t}$ is the total moisture fraction $\left(n_{t}=n_{v}+n_{l, i c e}\right)$ and $n_{d}$ is the dry gas fraction. It is assumed that any liquid condensate and ice that forms remains in the plume and thus the total water content is conserved.

The SCE are solved using the FPT, which transforms a continuous domain of masses (whilst conserving mass) into a discrete space of sections, each identified by the central mass of the bin, i.e. the pivot. The growth of the aggregates is described by the sticking efficiency between the particles and their collision frequencies. The approach is computationally efficient but can be affected by numerical diffusion if the number of bins is too coarse compared to the population under analysis. The coupling of the FPT with the one-dimensional buoyant plume model is applied at the level of the mass flux conservation equations. The mass flux is modified such that the mass fractions of the dry gas $\left(n_{d}\right)$, total moisture $\left(n_{t}\right.$, which is the mass fraction of vapour $\left(n_{v}\right)$ only, as neither liquid water or ice are entrained) and solid phases $\left(n_{s}\right)$ are treated separately:

$Q_{m}=\frac{d}{d s}\left[\left(\rho_{p} \pi b^{2} v_{p}\right) n_{d}\right]+\frac{d}{d s}\left[\left(\rho_{p} \pi b^{2} v_{p}\right) n_{t}\right]+\frac{d}{d s}\left[\left(\rho_{p} \pi b^{2} v_{p}\right) n_{s}\right]=E$

where $n_{d}+n_{t}+n_{v}=1$. As there is no entrainment of solids, Eq.14 can be expressed as:

$\frac{d}{d s}\left[\left(\rho_{p} \pi b^{2} v_{p}\right) n_{d}\right]+\frac{d}{d s}\left[\left(\rho_{p} \pi b^{2} v_{p}\right) n_{t}\right]=E$

$\frac{d}{d s}\left[\left(\rho_{p} \pi b^{2} v_{p}\right) n_{s}\right]=0$

We assume a discretized GSD composed of $N_{\text {bins }}$, where the mass fractions of a given size $\left(x_{i}\right)$ are divided across a set of bins, such that $\sum_{i=1}^{N_{\text {bins }}} x_{i}=1$. Assuming each size shares an amount of mass flux that is proportional to $x_{i}$, Eq. 16 becomes:

$\frac{d}{d s}\left[\left(\rho_{p} \pi b^{2} v_{p}\right) n_{s}\right] \sum_{n=1}^{N_{\text {bins }}} x_{i}=0 \rightarrow \sum_{i=1}^{N_{\text {bins }}} \frac{d}{d s}\left[\left(\rho_{p} \pi b^{2} v_{p}\right) n_{s} x_{i}\right]=0$

where we used the linearity of the sum with respect to the derivative operator. This is the continuity equation for solid mass flux in the case of a steady-state process. The continuity equation can be seen as a set of $N_{b i n s}$ equations, one for each $i$-th section, where aggregation is then taken into account by introducing source $\left(B_{i}\right)$ and sink $\left(D_{i}\right)$ terms in the right-hand side (rhs) of Eq.17. The continuity equation for the $i$-th bin then becomes:

$\frac{d}{d s}\left[\left(\rho_{p} \pi b^{2} v_{p}\right) n_{s} x_{i}\right]=b^{2} m_{i}\left[B_{i}-D_{i}\right]$

In the FPT the source term $B_{i}$ states that a given particle of the $i$-th section can be created when the sum of the masses $m_{s u m}$ of two interacting particles $k$ and $j$ is between the pivots $[i-1, i]$ and $[i, i+1]$. A fraction of $m_{s u m}$ is then proportionally attributed to the $i$-th pivot according to how close the mass $m_{\text {sum }}$ is to $m_{i}$. The redistribution of $m_{\text {sum }}$ among the bins is done in such a way that the mass is conserved by definition. The sink term $D_{i}$, on the other hand, is just related to the number of collisions 
and the sticking processes of the $i$-th particles with all the other pivots available, and there is no need to redistribute mass. The FPT applied to Eq.18 then becomes:

$$
\begin{aligned}
B_{i} & =\sum_{m_{i} \leq\left(m_{k}+m j\right)<m_{i+1}}\left(1-\frac{1}{2} \delta_{k j}\right)\left(\frac{m_{i+1}-m_{\text {sum }}}{m_{i+1}-m_{i}}\right) K_{k, j} N_{k} N_{j} \\
& +\sum_{m_{i-1} \leq\left(m_{k}+m j\right)<m_{i}}\left(1-\frac{1}{2} \delta_{k j}\right)\left(\frac{m_{\text {sum }}-m_{i-1}}{m_{i}-m_{i-1}}\right) K_{k, j} N_{k} N_{j} \\
D_{i} & =\sum_{j=1}^{N_{\text {bins }}} K_{i, j} N_{i} N_{j}
\end{aligned}
$$

where $N_{i}$ is the number of particles of a given mass per unit volume:

$$
N_{i}=\frac{\rho_{p} n_{s} x_{i}}{m_{i}}
$$

$145 K_{k, j}$ is the aggregation kernel between particles belonging to bins $k$ and $j$ respectively, and $\delta_{k j}$ is the Kronecker delta function. As such the SCE have been transformed into a set of Ordinary Differential Equations (ODEs) which are solved for each bin representing the $i$-th mass. The process of aggregation between two particles of mass $m_{k}$ and $m_{j}$, at a given location $s$ along the central axis of the plume, depends on the aggregation kernel $\left(K_{k, j}\right)$, which can be expressed in terms of the sticking efficiency $\left(\alpha_{k, j}\right)$ and the collision rate $\left(\beta_{k, j}\right)$ of particles:

$K_{k, j}=\alpha_{k, j} \beta_{k, j}$

where $\alpha_{k, j}$ is a dimensionless number between 0 and 1 which quantifies the probability of the particles successfully sticking together after a collision. $\beta_{k, j}$ describes the average volumetric flow of particles $\left(\mathrm{m}^{3} \mathrm{~s}^{-1}\right)$ involved in the collision between particles $k$ and $j$. We consider five different mechanisms, following Costa et al. (2010): Brownian motion $\left(\beta_{k, j}^{B}\right)$, interactions due to the differential settling velocities between the particles $\left(\beta_{k, j}^{D S}\right)$, and the interaction of particles due to turbulence: the inertial turbulent kernel $\left(\beta_{k, j}^{T I}\right)$ and the fluid shear, both laminar $\beta_{k, j}^{L S}$ and turbulent $\beta_{k, j}^{T S}$ :

$\beta_{k, j}^{B}=\frac{2 k_{B} T}{3 \mu_{a}} \frac{\left(d_{k}+d_{j}\right)^{2}}{d_{k} d_{j}}$

$\beta_{k, j}^{D S}=\frac{\pi}{4}\left(d_{k}+d_{j}\right)^{2}\left|V_{k}-V_{j}\right|$

160

$$
\begin{aligned}
& \beta_{k, j}^{T I}=\frac{1}{4} \frac{\pi \epsilon^{3 / 4}}{g \nu_{a}^{1 / 4}}\left(d_{k}+d_{j}\right)^{2}\left|V_{k}-V_{j}\right| \\
& \beta_{k, j}^{L S}=\frac{\Gamma}{6}\left(d_{k}+d_{j}\right)^{3}
\end{aligned}
$$


$\beta_{k, j}^{T S}=\left(\frac{1.7 \epsilon}{\nu_{a}}\right)^{1 / 2} \frac{1}{8}\left(d_{k}+d_{j}\right)^{3}$

where $d_{k}$ and $d_{j}$ are the diameters and $V_{k}$ and $V_{j}$ are the sedimentation velocities of the colliding particles:

$V_{k, j}=\sqrt{\left(\frac{4}{3} \frac{d_{k, j}}{C_{D}} g \frac{\rho_{s}-\rho_{a}}{\rho_{a}}\right)}$

where $C_{D}$ is the drag coefficient and $R e$ is the Reynolds number:

$C_{D}=\frac{24}{R e}\left(1+0.15 R e^{0.687}\right)$

$R e=\frac{V_{k, j} d_{k, j}}{\nu_{a}}$

and the sedimentation velocity is evaluated using an iterative scheme following Arastoopour et al. (1982). The laminar fluid shear is taken to be $\Gamma=\left|d w_{p} / d z\right|$. The dissipation rate of turbulent kinetic energy per unit mass $(\epsilon)$ is constrained by the parameters controlling the large-scale flow, the magnitude of velocity fluctuations (about $10 \%$ of the axial plume velocity) and the size of the largest eddies, which we take to be the plume radius (Textor and Ernst, 2004):

$175 \epsilon=\frac{\left(0.1 v_{p}\right)^{3}}{b}$

The total contribution from collisions due to each of the different mechanisms is represented by a linear superposition of each of the kernels (taking the maximum of the Shear Laminar and Shear Turbulent kernels):

$\beta_{k, j}=\beta_{k, j}^{B}+\operatorname{Max}\left(\beta_{k, j}^{L S}, \beta_{k, j}^{T S}\right)+\beta_{k, j}^{T I}+\beta_{k, j}^{D S}$

The different collision mechanisms are evaluated at each position $s$ along the central axis of the plume.

We assume that ash can stick together due to the presence of a layer of liquid water on the ash, following Costa et al. (2010). In this framework the energy involved in the collision of particles $k$ and $j$, identified from the relative kinetic energy of the bodies (i.e. rotations are not taken into account), can be parametrized in terms of the collision Stokes number $\left(S t_{v}\right)$ :

$S t_{v}=\frac{8 \hat{\rho} U_{r}}{9 \mu_{l}} \frac{d_{k} d_{j}}{d_{k}+d_{j}}$

which is a function of the average density of the two colliding particles $(\hat{\rho})$, the liquid viscosity $\left(\mu_{l}\right)$ and the relative velocities between the colliding particles $\left(U_{r}\right)$, here approximated as:

$U_{r}=\frac{8 k_{B} T}{3 \pi \mu_{a} d_{k} d_{j}}+\left|V_{k}-V_{j}\right|+\frac{4}{\pi} \Gamma_{\max }\left(d_{k}+d_{j}\right)$

$\Gamma_{\max }=\max \left(\frac{\Gamma}{6}, \frac{1}{8}\left(\frac{1.7 \epsilon}{\nu_{a}}\right)^{1 / 2}\right)$ 
Following a collision particles stick together if the relative kinetic energy of the colliding particles is completely depleted by viscous dissipation in the surface liquid layer on the particles (Liu et al., 2000). The condition for this to occur is given by:

$S t_{v}<S t_{c r}=\ln \left(\frac{h}{h_{a}}\right)$

where $h$ is the thickness of the liquid layer and $h_{a}$ is the surface asperity (Liu et al., 2000; Liu and Litster, 2002). Unfortunately this information is poorly constrained for volcanic ash. Costa et al. (2010) propose the following parameterization for the sticking efficiency:

$\alpha_{k, j}=\frac{1}{1+\left(\frac{S t_{v}}{S t_{c r}}\right)^{q}}$

using the experimental data of Gilbert and Lane (1994), which considered particles with diameters between 10 and $100 \mu \mathrm{m}$, and set $S t_{c r}=1.3$ and $q=0.8$ (see Figure 12 in Gilbert and Lane (1994) and Figure 1 in Costa et al. (2010)).

The influence of the ambient conditions, such as the relative humidity, on liquid bonding of ash aggregates still remains poorly constrained. Moreover, when trying to derive environmental conditions from one-dimensional plume models, it should be remembered that this description of a 3-dimensional turbulent flow simply represents an average of the flow conditions, and lacks details on local 'pockets' of liquid water due to clustering of the gas mixture (Cerminara et al., 2016b). In these local regions the concentration of water vapour can be high enough to reach the saturation condition and trigger the formation of liquid water. Further, aggregation can occur even when the bulk value of the relative humidity is relatively low (Telling and Dufek, 2012; Telling et al., 2013; Mueller et al., 2016). As such we allow sticking to occur in regions where the relative humidity is $<100 \%$ and liquid water is not yet present in the one-dimensional description of the plume, and we scale the sticking efficiency $\left(\alpha_{k, j}\right)$ by the relative humidity:

$\alpha_{k, j}=\alpha_{k, j} \cdot R H$

In the presence of ice we assume that the sticking efficiency is constant and $\alpha_{k, j}=0.09$, following Costa et al. (2010) and Field et al. (2006). 
Table 1: List of Latin symbols. Quantities with a superscript of 0 indicates values at the source.

\begin{tabular}{|c|c|c|c|}
\hline Symbol & Definition & Units & Comments \\
\hline$b$ & Plume Radius & $\mathrm{m}$ & - \\
\hline$B$ & Birth of mass & $\mathrm{m}^{-3} \mathrm{~s}^{-1}$ & - \\
\hline$C_{D}$ & Drag coefficient & - & \\
\hline$c_{p d}$ & Specific heat capacity of dry air & $\mathrm{J} \mathrm{K}^{-1} \mathrm{~kg}^{-1}$ & Value of 1005 \\
\hline$c_{p v}$ & Specific heat capacity of water vapour & $\mathrm{J} \mathrm{K}^{-1} \mathrm{~kg}^{-1}$ & Value of 1859 \\
\hline$c_{p l}$ & Specific heat capacity of liquid water & $\mathrm{J} \mathrm{K}^{-1} \mathrm{~kg}^{-1}$ & Value of 4183 \\
\hline$c_{p p}$ & Bulk specific heat capacity of plume & $\mathrm{J} \mathrm{K}^{-1} \mathrm{~kg}^{-1}$ & - \\
\hline$D$ & Death of mass & $\mathrm{m}^{-3} \mathrm{~s}^{-1}$ & - \\
\hline$d$ & Particle diameter & $\mathrm{m}$ & - \\
\hline$E$ & Entrainment rate & $\mathrm{kg} \mathrm{m}^{-2} \mathrm{~s}^{-1}$ & - \\
\hline$e_{o}$ & Restitution coefficient of dry particles & - & Value of 0.7 \\
\hline$e_{s}$ & Saturation vapour pressure & $\mathrm{Pa}$ & - \\
\hline$g$ & Acceleration due to gravity & $\mathrm{m} \mathrm{s}^{-2}$ & Value of 9.81 \\
\hline$H$ & Enthalpy flux & $\mathrm{J} \mathrm{s}^{-1}$ & - \\
\hline$h$ & Thickness of liquid layer & $\mathrm{m}$ & - \\
\hline$h_{a}$ & Height of surface asperity & $\mathrm{m}$ & - \\
\hline$K$ & Collision kernel & $\mathrm{m}^{3} \mathrm{~s}^{-1}$ & - \\
\hline$k_{B}$ & Boltzman constant & $\mathrm{J} \mathrm{K}^{-1}$ & Value of $1.38 \times 10^{-23}$ \\
\hline$k_{s}$ & Entrainment coefficient normal to plume axis & - & Default 0.1 \\
\hline$k_{n}$ & Entrainment coefficient perpendicular to plume axis & - & Default 0.5 \\
\hline$L_{v o}$ & Latent heat of vapourisation at $0^{\circ} \mathrm{C}$ & $\mathrm{MJ} \mathrm{kg}^{-1}$ & Value of 2.5 \\
\hline$m$ & Mass & $\mathrm{kg}$ & - \\
\hline$m_{32}$ & Mass fraction on $d \leq 32 \mu \mathrm{m}$ & - & - \\
\hline$N$ & Number of particles & - & - \\
\hline$n_{l}$ & Mass fraction of liquid water & - & - \\
\hline$n_{i c e}$ & Mass fraction of ice & - & - \\
\hline$n_{d}$ & Mass fraction of dry air & - & Default $n_{d}^{0}=0.03$ \\
\hline$n_{v}$ & Mass fraction of water vapour & - & Default $n_{v}^{0}=0.00$ \\
\hline$n_{g}$ & Mass fraction of gas & - & $n_{g}=n_{d}+n_{v}$ \\
\hline$n_{s}$ & Mass fraction of solids & - & - \\
\hline$n_{t}$ & Mass fraction of total moisture content & - & $n_{t}=n_{v}+n_{l, i c e}$ \\
\hline$p_{d}$ & Dry ambient pressure & $\mathrm{Pa}$ & - \\
\hline
\end{tabular}




\begin{tabular}{|c|c|c|c|}
\hline$Q_{l}$ & Flux of liquid water in plume & $\mathrm{kg} \mathrm{s}^{-1}$ & $Q_{l}=n_{l} Q_{m}$ \\
\hline$Q_{m}$ & Mass flux & $\mathrm{kg} \mathrm{s}^{-1}$ & - \\
\hline$Q_{t}$ & Total moisture flux & $\mathrm{kg} \mathrm{s}^{-1}$ & - \\
\hline$q$ & Sticking parameter & - & Default 0.8 \\
\hline$q_{v}^{a}$ & Ambient Specific humidity & $\mathrm{kg} \mathrm{kg}^{-1}$ & \\
\hline Re & Reynolds Number & - & - \\
\hline$r_{s}$ & Saturation mixing ratio & - & - \\
\hline$S t_{c r}$ & Critical Stokes number & - & Default 1.3 \\
\hline$S t_{v}$ & Collision Stokes number & - & - \\
\hline$s$ & Distance along the plume axis & $\mathrm{m}$ & - \\
\hline$T$ & Temperature & $\mathrm{K}$ & Default 1273 \\
\hline$t$ & Time & $\mathrm{s}$ & - \\
\hline $\mathbf{U}$ & Ambient wind velocity & $\mathrm{m} \mathrm{s}^{-1}$ & $\mathbf{U}=\mathbf{U}(\mathbf{z})$ \\
\hline$U_{r}$ & Relative velocity of colliding particles & $\mathrm{m} \mathrm{s}^{-1}$ & - \\
\hline$u_{e}$ & Entrainment velocity & $\mathrm{m} \mathrm{s}^{-1}$ & - \\
\hline $\mathbf{u}_{p}$ & Horizontal plume velocity & $\mathrm{m} \mathrm{s}^{-1}$ & - \\
\hline $\mathbf{u}_{n}$ & Relative velocity perpendicular to the plume radius & $\mathrm{m} \mathrm{s}^{-1}$ & - \\
\hline $\mathbf{u}_{s}$ & Relative velocity parallel to the plume radius & $\mathrm{m} \mathrm{s}^{-1}$ & - \\
\hline$V$ & Particle sedimentation velocity & $\mathrm{m} \mathrm{s}^{-1}$ & - \\
\hline$v_{p}$ & Magnitude of velocity along plume axis & & $v_{p}=\sqrt{u_{p x}^{2}+u_{p y}^{2}+w_{p}^{2}}$ \\
\hline$w_{p}$ & Vertical component of plume velocity & $\mathrm{m} \mathrm{s}^{-1}$ & - \\
\hline$x$ & Mass fraction on a given particle class & - & - \\
\hline \multicolumn{4}{|c|}{ Subscripts } \\
\hline$i$ & Sections (bins) & & \\
\hline$j, k$ & Particle size classes (from 1 to $N_{\text {bins }}$ ) & & \\
\hline ice & Ice & & \\
\hline$l$ & Liquid & & \\
\hline$v$ & Vapour & & \\
\hline$d$ & Dry air & & \\
\hline$t$ & Total moisture content & & \\
\hline$s$ & Solid phase & & \\
\hline$p$ & Plume & & \\
\hline$x, y$ & Horizontal coordinates & & \\
\hline$z$ & Vertical coordinate & & \\
\hline
\end{tabular}


Table 2. List of Greek symbols.

\begin{tabular}{|c|c|c|c|}
\hline Symbol & Definition & Units & Comments \\
\hline$\alpha$ & Sticking efficiency & - & - \\
\hline$\beta$ & Collision rate & $\mathrm{m}^{3} \mathrm{~s}^{-1}$ & - \\
\hline$\beta^{B}$ & Collision rate due to Brownian motion & $\mathrm{m}^{3} \mathrm{~s}^{-1}$ & - \\
\hline$\beta^{D S}$ & Collision rate due to differential settling & $\mathrm{m}^{3} \mathrm{~s}^{-1}$ & - \\
\hline$\beta^{T I}$ & Collision rate due to inertia & $\mathrm{m}^{3} \mathrm{~s}^{-1}$ & - \\
\hline$\beta^{L S}$ & Collision rate due to laminar fluid shear & $\mathrm{m}^{3} \mathrm{~s}^{-1}$ & - \\
\hline$\beta^{T S}$ & Collision rate due to turbulent fluid shear & $\mathrm{m}^{3} \mathrm{~s}^{-1}$ & - \\
\hline$\delta_{k j}$ & Kronecker delta function & - & - \\
\hline$\epsilon$ & Dissipation rate of turbulent kinetic energy & $\mathrm{m}^{2} \mathrm{~s}^{-3}$ & - \\
\hline$\varepsilon$ & Molecular mass of water vapour to dry air & - & Value 0.62 \\
\hline$\Gamma$ & Fluid Shear & $\mathrm{s}^{-1}$ & - \\
\hline$\mu_{l}$ & Dynamic viscosity of water & $\mathrm{Pa} \mathrm{s}$ & Value $5.43 \times 10^{-4}$ \\
\hline$\mu_{a}$ & Dynamic viscosity of air & $\mathrm{Pa} \mathrm{s}$ & Value $1.83 \times 10^{-5}$ \\
\hline$\nu_{a}$ & Kinematic viscosity of air & $\mathrm{m}^{2} \mathrm{~s}^{-1}$ & - \\
\hline$\rho_{a}$ & Ambient density & $\mathrm{kg} \mathrm{m}^{-3}$ & - \\
\hline$\rho_{p}$ & Plume density & $\mathrm{kg} \mathrm{m}^{-3}$ & - \\
\hline$\rho_{l}$ & Liquid density & $\mathrm{kg} \mathrm{m}^{-3}$ & - \\
\hline$\rho_{s}$ & Particle density & $\mathrm{kg} \mathrm{m}^{-3}$ & Default 2000 \\
\hline$\rho_{\text {agg }}$ & Aggregate density & $\mathrm{kg} \mathrm{m}^{-3}$ & - \\
\hline$\hat{\rho}$ & Average density of two colliding particles & $\mathrm{kg} \mathrm{m}^{-3}$ & - \\
\hline
\end{tabular}

2103 Aggregation Model Sensitivities

To consider the influence of uncertainty on the source and internal model parameters on the simulated AGSD we have conducted a simple sensitivity study whereby the input parameters are varied one at a time. As such we assess the difference between the simulated output using the set of default parameters (the control case) from a perturbed case. This approach assumes model variables are independent when considering the effects of each on model predictions.

For our case study we consider the ash plume from the 2010 eruption of Eyjafjallajökull volcano, Iceland (location $63.63^{\circ}$ lat, $-19.62^{\circ}$ lon, summit height $1666 \mathrm{~m}$ asl) between 04/05/2010 - 08/05/2010. We use the time-profile of plume heights given in Webster et al. (2012) which are based on a best-guess set of observations. Meteorological data are from the Global configuration of the Unified Model (UM) which, for this period, had a horizontal resolution of $\sim 25 \mathrm{~km}$ (at mid-latitudes) and a temporal resolution of 3 hours. The control values used for the source and internal model parameters in the aggregation scheme are given in Table 3, along with the range of values for each parameter considered in the sensitivity study. Values are based on the existing literature and the sources used are also listed in Table 3. The scheme is initialized with a GSD with diameters 
ranging from $1 \mu \mathrm{m}$ to $16 \mathrm{~mm}$. Bins are defined on the Phi Scale, where the Phi diameter is calculated as the negative logarithm to the base 2 of the particle diameter in millimeters (Krumbein, 1938). The mass is distributed uniformly across the bins such that $50 \%$ is on grains with diameter $\leq 125 \mu \mathrm{m}$ and $36 \%$ of the mass is on grains with diameter $\leq 32 \mu \mathrm{m}$. The output AGSD at the top of the plume, defined as the point at which $W_{p}<0$, is assessed. Given the nature of the SCE, the aggregation scheme does not track explicitly the mass fraction of aggregates versus single grains within a given size bin. Instead we consider how the mode of the output AGSD varies, and compare the mass fraction on particles with diameter $\leq 32 \mu \mathrm{m}\left(\mathrm{m}_{32}\right)$, which predominantly lose mass to larger aggregates, for each sensitivity run.

First, we consider how the AGSD varies as conditions within the plume change over time given the local meteorological and eruption conditions (plume height). Figure 1 shows the relative humidity $(\mathrm{RH})$, temperature $(T)$ and the fractions of liquid water $\left(n_{l}\right)$, water vapour $\left(n_{v}\right)$ and ice $\left(n_{i}\right)$ with height along the plume axis at different times during the eruption. Note that the maximum height of the modelled plume axis, when the plume is bent over as in this case, is the maximum observed plume height minus the plume radius (Mastin, 2014; Devenish, 2016). At 19:00 UTC on the 04/05/2010 the maximum observed plume height is $7000 \mathrm{~m}$ asl, liquid water starts to form at $4122 \mathrm{~m}$ asl, but no ice forms in the plume. At 12:00 UTC on the 05/05/2010 the observed maximum plume height is lower, reaching just $5500 \mathrm{~m}$ asl, liquid water is present from $3684 \mathrm{~m}$ asl and again no ice is formed. However, at 13:00 UTC on the 06/05/2010 no liquid water forms in the plume, only ice, which is present from $5882 \mathrm{~m}$ asl and the maximum observed plume height is 10,000 $\mathrm{m}$ asl. At 12:00 UTC on the 07/05/2010 the maximum observed plume height is $5500 \mathrm{~m}$ asl and there is neither liquid water or ice in the plume, only water vapour. Figure 2 shows the output AGSDs for each of these times, compared to the input GSD. We find that in all the cases considered the mode of the AGSD is always the same, with most of the mass now residing in the $125-250 \mu \mathrm{m}$ bin. When ash spends more time in the presence of liquid water $m_{32}$ decreases slightly: $m_{32}=32 \%$ at 19:00 UTC 04/05/2010 when liquid water is present from $4122 \mathrm{~m}$ asl, but $\mathrm{m}_{32}=33 \%$ at 12:00 UTC 05/05/2010 when liquid water is only available over a more limited depth (Figures 2a and 2b). Aggregation still occurs when there is only ice present and no liquid water (06/05/2010 13:00, Figure 2c), and when there is no ice or liquid water present (12:00 UTC 07/05/2010, Figure 2d).

The mode and $\mathrm{m}_{32}$ of the simulated AGSD for each sensitivity run output at 19:00 04/05/2010 are listed in Table 4. Using the control parameters the mode of the AGSD lies at $125-250 \mu \mathrm{m}$ and $\mathrm{m}_{32}$ is $32 \%$ at this time (c.f. Figure 2a). The aggregation scheme is sensitive to the values assigned to the sticking parameters $\left(S t_{c r}\right.$ and $\left.q\right)$ and the parameters which define the particle characteristics, the input GSD and the particle density (note that here all model particles are assigned the same density, as such $\hat{\rho}=\rho_{s}$ ). Figure 3 shows how the cumulative distribution of the AGSD changes as these parameters are varied within their known ranges. The parameters used to set the sticking efficiency between the particles $\left(S t_{c r}\right.$ and $q$ ) are currently poorly understood, and therefore under-constrained. Figures 3a-b show the aggregated GSD when $S t_{c r}$ and $q$ are varied by a factor of 2. When $q=0.4, \mathrm{~m}_{32}$ is $30 \%$ and the mode of the AGSD moves to $500-1000 \mu \mathrm{m}$, when $q=1.6$ the mode lies at $64-125$ $\mu \mathrm{m}$, and for $S t_{c r}$ in the range $0.65-2.6 \mathrm{~m}_{32}$ varies from $31-33 \%$. When particles have a (low) density of $500 \mathrm{~kg} \mathrm{~m}^{-3} \mathrm{~m}_{32}$ is $24 \%$ and the modal bin is $500-1000 \mu \mathrm{m}$ (Figure 3c). We find that using a relatively coarse input GSD (from the eruption of Hekla 1991) there is very little aggregation; there is no change in $m_{32}$ or the modal grain size (Figure 3d) from the input GSD. Whereas using the Eyjafjallajökull 2010 GSD, which is much finer, the mode of the AGSD is shifted to larger sizes. 
Table 3. Model variables used in the aggregation scheme to represent the eruption conditions. The control values listed for each parameter are based on the defaults used in the existing literature. The range of parameter values considered in the sensitivity study are also given.

\begin{tabular}{|c|c|c|c|c|}
\hline & Model Variable & Control Value & Range Considered & References \\
\hline $\begin{array}{l}\text { Plume } \\
\text { Properties }\end{array}$ & $\begin{array}{l}\text { Entrainment coefficient: } \\
\text { normal }\left(k_{s}\right) \\
\text { perpendicular }\left(k_{n}\right) \\
\text { Source plume temperature }\left(T_{0}\right) \\
\text { Source mass fraction of: } \\
\text { dry air }\left(n_{d}^{0}\right) \\
\text { water vapour }\left(n_{v}^{0}\right) \\
\text { Mass Flux }\left(Q_{m}\right)\end{array}$ & $\begin{array}{l}0.1 \\
0.5 \\
1273 \mathrm{~K} \\
0.03 \\
0.0 \\
\text { Plume Scheme }\end{array}$ & $\begin{array}{l}0.05-0.15 \\
0.4-0.9 \\
953-1373 \mathrm{~K} \\
0.01-0.03 \\
0.0-0.05 \\
Q_{m} \times 0.1-\times 10\end{array}$ & $\begin{array}{l}\text { Woodhouse et al. (2016) } \\
\text { Aubry et al. (2017); Costa et al. (2016) } \\
\text { Woodhouse et al. (2016) } \\
\text { Devenish (2013); Woods (1988) } \\
\text { Devenish (2013); Costa et al. (2016) } \\
\text { Costa et al. (2016) }\end{array}$ \\
\hline $\begin{array}{l}\text { Aggregation } \\
\text { Properties }\end{array}$ & $\begin{array}{l}\text { Critical Stokes number }\left(S t_{c r}\right) \\
\text { Sticking parameter }(q)\end{array}$ & $\begin{array}{l}1.3 \\
0.8\end{array}$ & $\begin{array}{l}0.65-2.6 \\
0.4-1.6\end{array}$ & $\begin{array}{l}\text { Costa et al. (2010); Gilbert and Lane (1994) } \\
\text { Costa et al. (2010); Gilbert and Lane (1994) }\end{array}$ \\
\hline $\begin{array}{l}\text { Ash } \\
\text { Properties } \\
\text { (non-aggregated) }\end{array}$ & $\begin{array}{l}\text { Ash density }\left(\rho_{s}\right) \\
\text { GSD }\end{array}$ & $\begin{array}{l}2000 \mathrm{~kg} \mathrm{~m}^{-3} \\
\text { Uniform } \\
\mathrm{m}_{32} 36 \%\end{array}$ & $\begin{array}{l}500 \text { - } 3000 \mathrm{~kg} \mathrm{~m}^{-3} \\
\text { Eyjafjallajökull } 2010 \text { (fine), } \\
\text { mode } 500 \text { - } 1000 \mu \mathrm{m}, m_{32}, 26 \% \\
\text { Hekla } 1991 \text { (coarse) } \\
\text { mode } 8000 \text { - } 16000 \mu \mathrm{m}, m_{32} 2 \%\end{array}$ & $\begin{array}{l}\text { Bonadonna and Phillips (2003) } \\
\text { Bonadonna et al. (2011) } \\
\text { Gudnason et al. (2017); }\end{array}$ \\
\hline
\end{tabular}

Output from the sensitivity runs for other times during the eruption (corresponding to those in Figure 2) are provided in the Supplementary Material and show the same behaviour (Figures S1 - S3).

The AGSD shows little sensitivity to the model values assigned to define the plume conditions within the ranges investigated: the entrainment parameters $\left(k_{s}\right.$ and $\left.k_{n}\right)$, the initial mass fraction of dry gas and water vapour $\left(n_{d}^{0}, n_{v}^{0}\right)$, the plume temperature at the source $\left(\mathrm{T}_{0}\right)$ or the source mass flux $\left(Q_{m}\right)$ (see Table 4 and Supplementary Figures S4 - S7). When we consider that the mass flux may have an order of magnitude uncertainty, and vary the input mass flux to the aggregation scheme by a factor of $10 \mathrm{~m}_{32}$ varies by just $1 \%$. 
Table 4. Properties of the simulated AGSD from the model sensitivity runs, output is for 19:00 UTC 04/05/2010. Using control values (Table 3) the mode is at $125-250 \mu \mathrm{m}$ and $m_{32} 32 \%$

\begin{tabular}{|c|c|c|c|c|}
\hline & $\begin{array}{l}\text { Model } \\
\text { Variable }\end{array}$ & Value & Mode & $\mathrm{m}_{32}$ \\
\hline $\begin{array}{l}\text { Plume } \\
\text { Properties }\end{array}$ & $\begin{array}{l}k_{s} \\
k_{n} \\
T_{0} \\
n_{d}^{0} \\
n_{v}^{0} \\
Q_{m}\end{array}$ & $\begin{array}{l}0.05 \\
0.15 \\
0.4 \\
0.9 \\
953 \mathrm{~K} \\
1373 \mathrm{~K} \\
0.01 \\
0.02 \\
0.03 \\
0.05 \\
0.1 Q_{m} \\
10 Q_{m}\end{array}$ & $\begin{array}{l}125-250 \mu \mathrm{m} \\
125-250 \mu \mathrm{m} \\
125-250 \mu \mathrm{m} \\
125-250 \mu \mathrm{m} \\
125-250 \mu \mathrm{m} \\
125-250 \mu \mathrm{m} \\
125-250 \mu \mathrm{m} \\
125-250 \mu \mathrm{m} \\
125-250 \mu \mathrm{m} \\
125-250 \mu \mathrm{m} \\
125-250 \mu \mathrm{m} \\
125-250 \mu \mathrm{m}\end{array}$ & $\begin{array}{l}32 \% \\
32 \% \\
32 \% \\
33 \% \\
30 \% \\
32 \% \\
32 \% \\
32 \% \\
32 \% \\
32 \% \\
33 \% \\
31 \%\end{array}$ \\
\hline $\begin{array}{l}\text { Aggregation } \\
\text { Properties }\end{array}$ & $S t_{c r}$ & $\begin{array}{l}0.65 \\
2.6 \\
0.4 \\
1.6\end{array}$ & $\begin{array}{l}125-250 \mu \mathrm{m} \\
125-250 \mu \mathrm{m} \\
500-1000 \mu \mathrm{m} \\
64-125 \mu \mathrm{m}\end{array}$ & $\begin{array}{l}33 \% \\
31 \% \\
30 \% \\
33 \%\end{array}$ \\
\hline $\begin{array}{l}\text { Particle } \\
\text { Properties }\end{array}$ & GSD & $\begin{array}{l}500 \mathrm{~kg} \mathrm{~m}^{-3} \\
3000 \mathrm{~kg} \mathrm{~m}^{-3} \\
\text { Eyjafjallajökull } 2010 \\
\text { Hekla } 1991\end{array}$ & $\begin{array}{l}500-1000 \mu \mathrm{m} \\
125-250 \mu \mathrm{m} \\
500-1000 \mu \mathrm{m} \\
8000-16000 \mu \mathrm{m}\end{array}$ & $\begin{array}{l}24 \% \\
33 \% \\
\\
23 \% \\
2 \%\end{array}$ \\
\hline
\end{tabular}



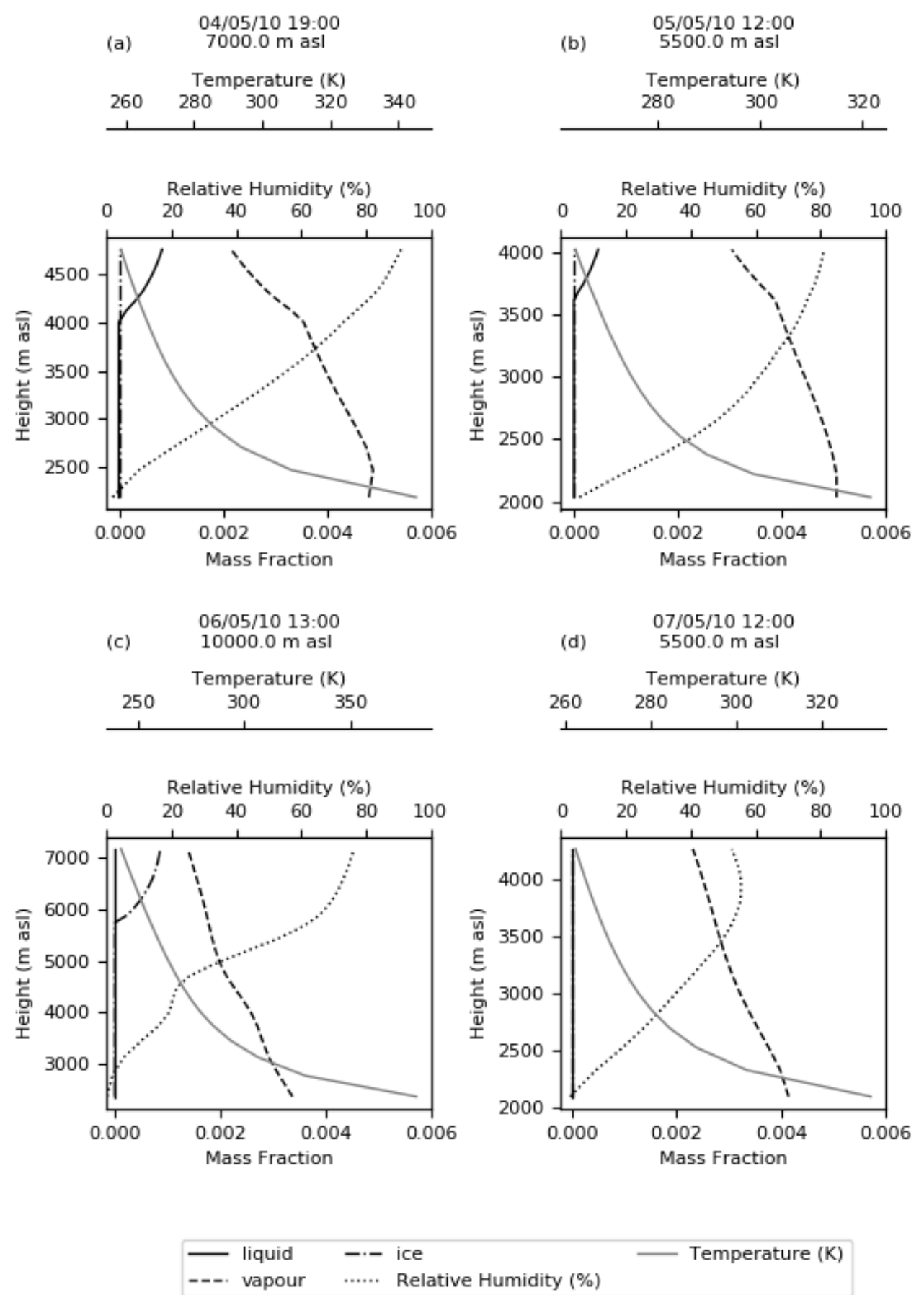

Figure 1. The fractions of water vapour $\left(n_{v}\right)$, liquid water $\left(n_{l}\right)$ and ice $\left(n_{i c e}\right)$ with height along the buoyant plume axis, for the eruption of Eyjafjallajökull volcano between the 4th and 7th May 2010. Also shown are the relative humidity and temperature. Note the variation in axis scales. 
https://doi.org/10.5194/acp-2021-254

Preprint. Discussion started: 31 May 2021

(c) Author(s) 2021. CC BY 4.0 License.
Atmospheric

Chemistry and Physics

Discussions (a) $\quad 04 / 05 / 1019: 00$

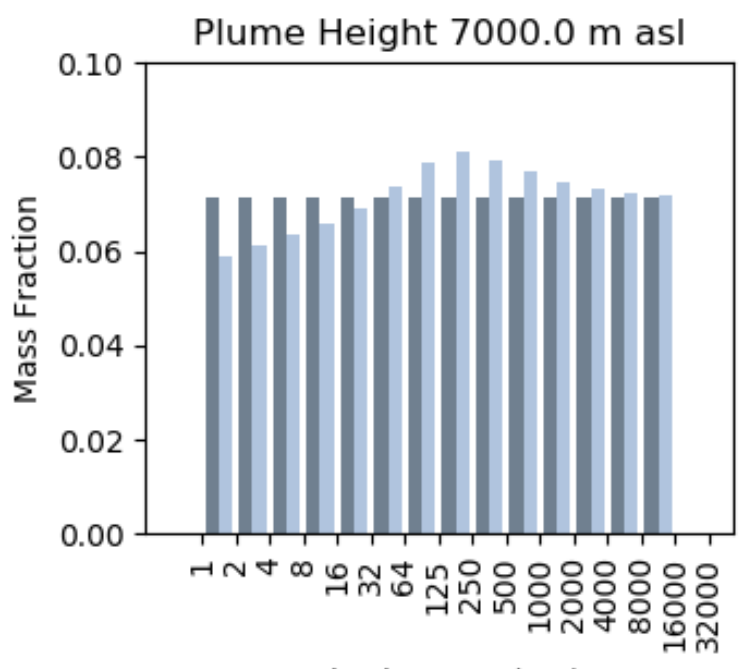

Ash Diameter $(\mu \mathrm{m})$

(c) $\quad 06 / 05 / 1013: 00$

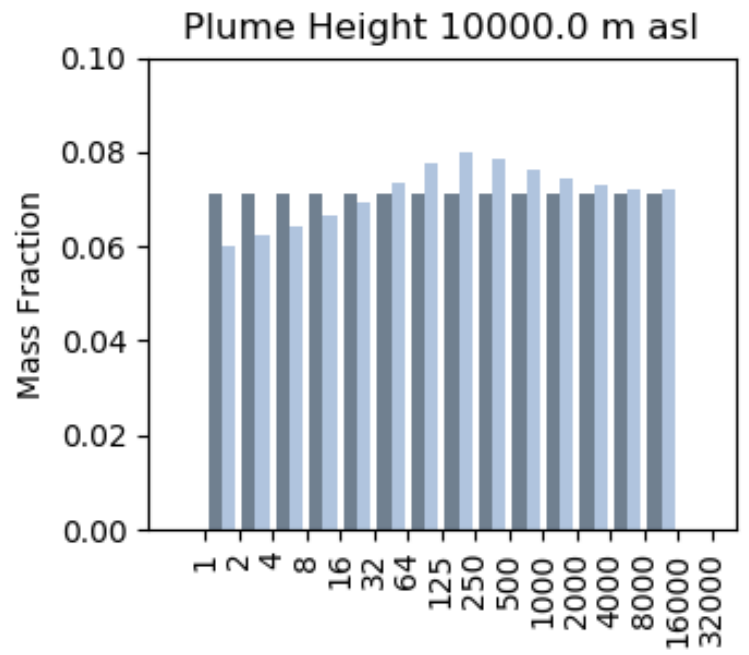

Ash Diameter $(\mu \mathrm{m})$ (b) $\quad 05 / 05 / 1012: 00$

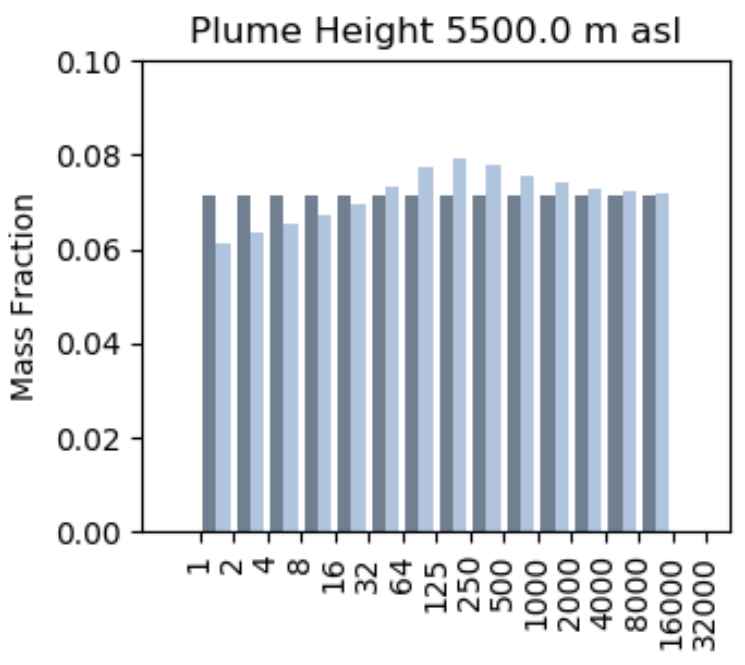

Ash Diameter $(\mu \mathrm{m})$

(d) $\quad 07 / 05 / 1012: 00$

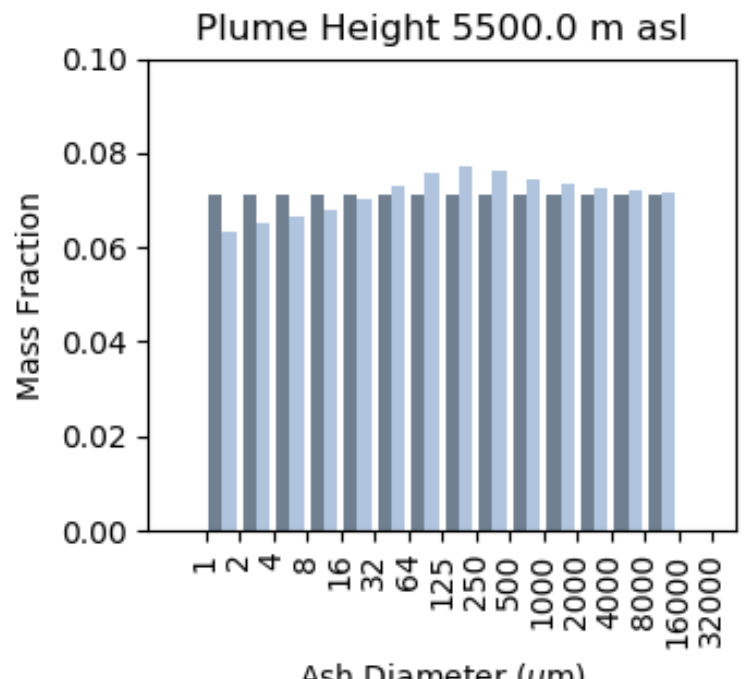

Ash Diameter $(\mu \mathrm{m})$

Input Uniform GSD

Output Aggregated GSD

Figure 2. Modelled AGSDs corresponding to the times and phase conditions shown in Figure 1. 
(a)

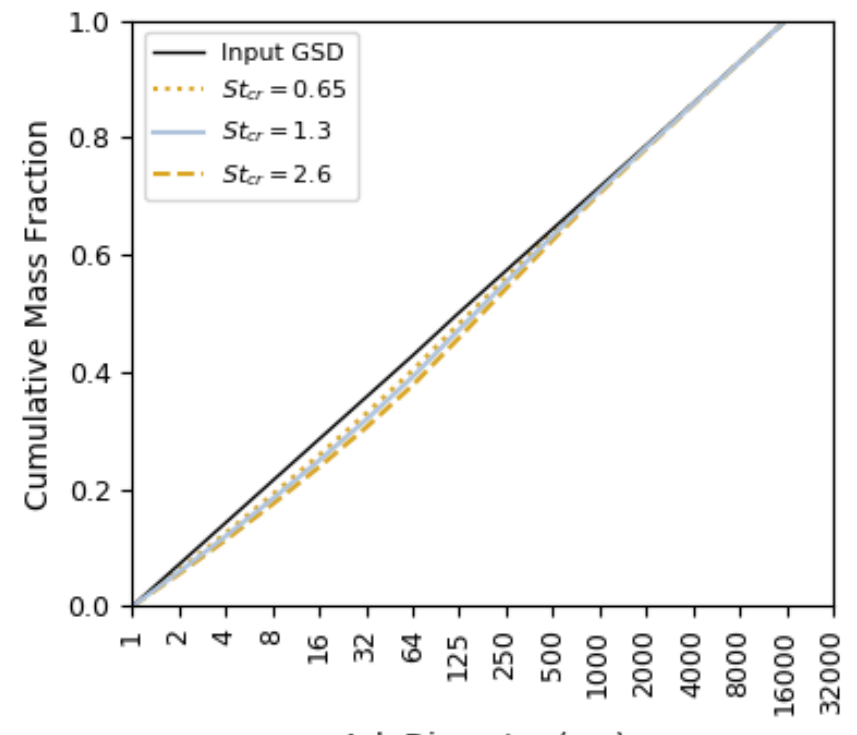

Ash Diameter $(\mu \mathrm{m})$

(c)

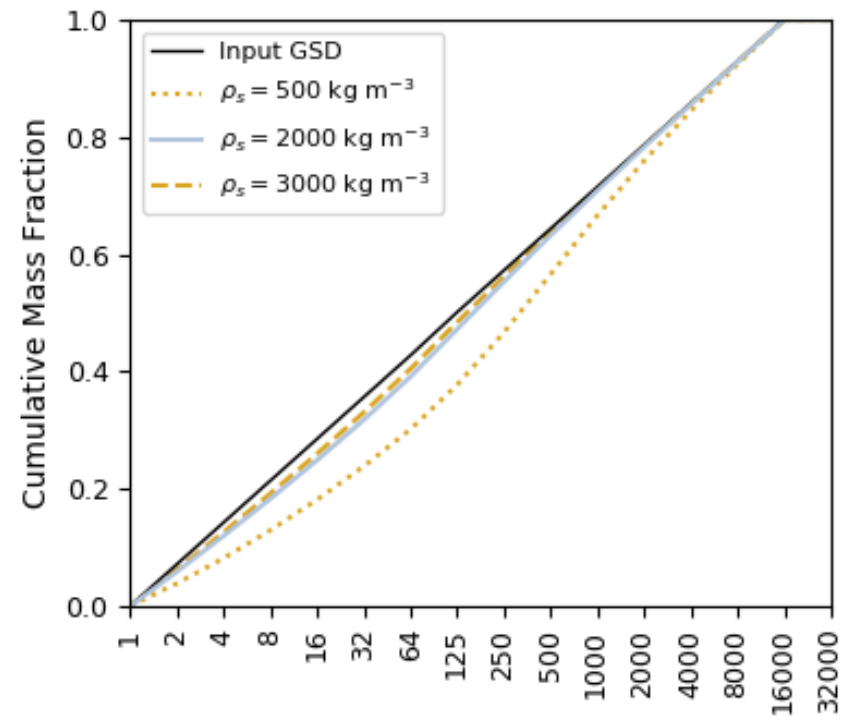

Ash Diameter $(\mu \mathrm{m})$ (b)

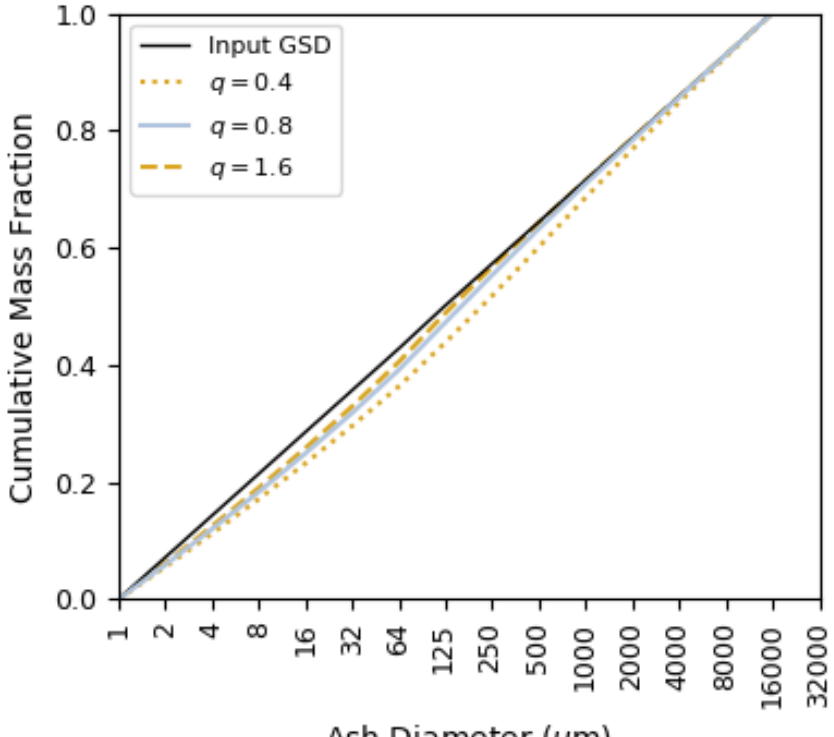

Ash Diameter $(\mu \mathrm{m})$

(d)

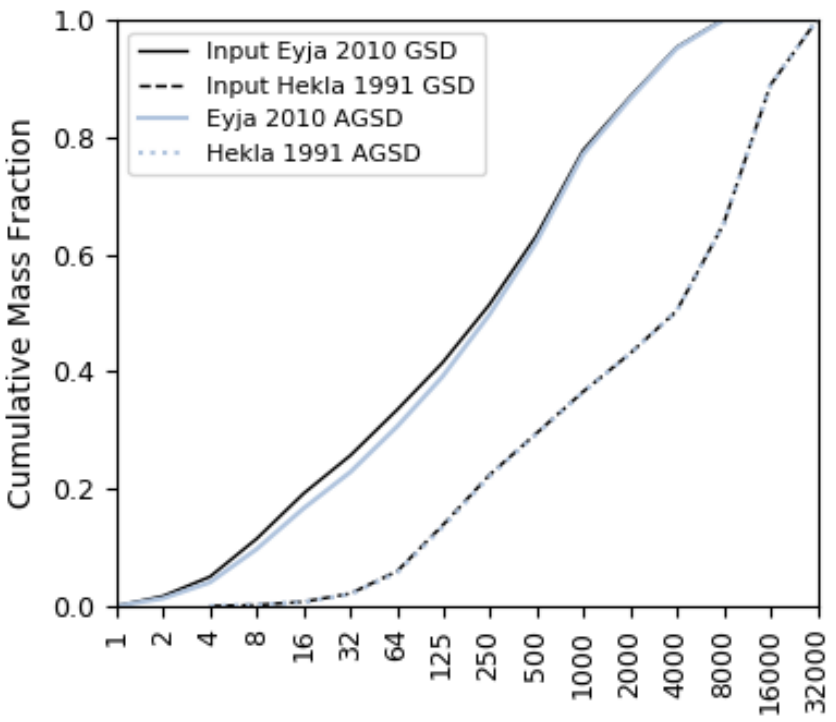

Ash Diameter $(\mu \mathrm{m})$

Figure 3. Sensitivity of the output aggregated GSD to the sticking efficiency parameters (a) $S t_{c r}$, (b) $q$, and the physical characteristics assigned to the particles, (c) particle density $\rho_{s}$ and (d) input GSD. Output is for 19:00 UTC on the 04/05/2010, plume height 7000 m asl (c.f. Figure 2a). Note that the blue lines represent simulations using the control values. 


\section{Scale Analysis of the Collision Kernel}

In order to gain more insight into the dependence of the collision kernel on $q, S t_{c r}$ and $\rho_{s}$ we consider a scale analysis of $\alpha_{k, j}$ and $\beta_{k, j}$ in turn. Starting with the collision rate we can write Eq. 32 as

$\beta_{k, j}=\mathcal{B} \frac{\left(d_{k}+d_{j}\right)^{2}}{d_{k} d_{j}}+\mathcal{S}\left(d_{k}+d_{j}\right)^{3}+\mathcal{I}\left(d_{k}+d_{j}\right)^{2}\left|d_{k}^{2}-d_{j}^{2}\right|+\mathcal{D}\left(d_{k}+d_{j}\right)^{2}\left|d_{k}^{2}-d_{j}^{2}\right|$

where

$\mathcal{B}=\frac{2 k_{b} T}{3 \mu_{a}} \quad \mathcal{S}=\frac{1}{8}\left(\frac{1.7 \epsilon}{\nu_{a}}\right)^{1 / 2} \quad \mathcal{I}=\frac{1}{72} \frac{\pi \epsilon^{3 / 4}}{\nu_{a}^{1 / 4}} \frac{\rho_{s}}{\mu_{a}} \quad \mathcal{D}=\frac{\pi}{4} \frac{g \rho_{s}}{18 \mu_{a}}$

are taken to be constant (including $\rho_{s}$ ). Here we have assumed that the particles settle with Stokes' terminal velocity (i.e. we neglect the second term on the rhs of Eq. 29); this will lead to quantitative discrepancies with the collision kernel calculated in Section 3 for larger diameters but the qualitative behaviour will be correct. We have also assumed that $\beta_{i, j}^{T S}>\beta_{i, j}^{L S}$; this assumption does not affect our conclusions below. Since aggregation is associated with the presence of liquid water or ice and $\alpha_{k, j}$ only depends on $q$ and $S t_{c r}$ in the former case, we choose values of the constituent parameters in Eq. 40 that are appropriate for the formation of liquid water. Thus, with $T=300 \mathrm{~K}, \epsilon=0.01 \mathrm{~m}^{2} \mathrm{~s}^{-3}, \rho_{a}=1.297 \mathrm{~kg} \mathrm{~m}^{-3}$ and $\rho_{s}=2000 \mathrm{~kg}$ $\mathrm{m}^{-3}$ the constants in Eq. 40 have the following orders of magnitude:

$\mathcal{B} \sim 10^{-16} \quad \mathrm{~m}^{3} \mathrm{~s}^{-1} \quad \mathcal{S} \sim 1 \quad \mathrm{~s}^{-1} \quad \mathcal{I} \sim 10^{6} \quad \mathrm{~m}^{-1} \mathrm{~s}^{-1} \quad \mathcal{D} \sim 10^{7} \quad \mathrm{~m}^{-1} \mathrm{~s}^{-1}$

As in Section 3 we restrict attention to diameters in the range $\left[1,10^{4}\right] \mu \mathrm{m}$. Figure 4 shows the variation of $\beta_{k, j}$ given by Eq. 39 with $d_{k}$ for three fixed values of $d_{j}$. The difference between assuming Stokes' terminal velocity and using the terminal velocity as given by Eqs (28)-(30) becomes clear for large diameters. Note that $\beta_{k, j}$ is symmetric in the indices $j$ and $k$.

In the special case that $d_{k}=d_{j}$ Eq. 39 becomes

$\beta_{j, j}=4 \mathcal{B}+8 \mathcal{S} d_{j}^{3}$

For $d_{j} \sim 1 \mu \mathrm{m}$ the first term dominates. The second term dominates for all values of $d_{j} \gtrsim 10 \mu \mathrm{m}$ : for $d_{j} \sim 10 \mu \mathrm{m}$ we get $\beta_{j, j} \sim 10^{-14} \mathrm{~m}^{3} \mathrm{~s}^{-1}$; for $d_{j} \sim 100 \mu \mathrm{m}$ we get $\beta_{j, j} \sim 10^{-11} \mathrm{~m}^{3} \mathrm{~s}^{-1}$; for $d_{j} \sim 1000 \mu \mathrm{m}$ we get $\beta_{j, j} \sim 10^{-8} \mathrm{~m}^{3} \mathrm{~s}^{-1}$.

In the case that $d_{k} \ll d_{j}$ Eq. 39 becomes

$\beta_{k, j} \approx \mathcal{B} \frac{d_{j}}{d_{k}}+\mathcal{S} d_{j}^{3}+\mathcal{I} d_{j}^{4}+\mathcal{D} d_{j}^{4}$

Scale analysis (using the values above) shows that the third term can be neglected and the second term is only comparable with the last term when $d_{j} \sim 0.1 \mu \mathrm{m}$ which is outside the range of interest. Noting that the smallest values of $d_{j}, d_{k} \in\left[1,10^{4}\right] \mu \mathrm{m}$ that satisfy $d_{k} \ll d_{j}$ are $d_{j} \sim 10 \mu \mathrm{m}$ and $d_{k} \sim 1 \mu \mathrm{m}$ we see that, for all $d_{j} \gtrsim 10 \mu \mathrm{m}$, the fourth term will dominate and so $\beta_{k, j}$ is effectively constant (since we are considering fixed $d_{j}$ ). Thus, for $d_{j} \sim 10 \mu \mathrm{m}$ we get $\beta_{k, j} \sim 10^{-13} \mathrm{~m}^{3} \mathrm{~s}^{-1}$; for $d_{j} \sim 100$ $\mu \mathrm{m}$ we get $\beta_{k, j} \sim 10^{-9} \mathrm{~m}^{3} \mathrm{~s}^{-1}$; for $d_{j} \sim 1000 \mu \mathrm{m}$ we get $\beta_{k, j} \sim 10^{-5} \mathrm{~m}^{3} \mathrm{~s}^{-1}$. These are consistent with what is observed in Figure 4 for $d_{k} \ll d_{j}$. Furthermore we note that these values are all larger than the values of $\beta_{k, j}$ in the special case $d_{k}=d_{j}$ 


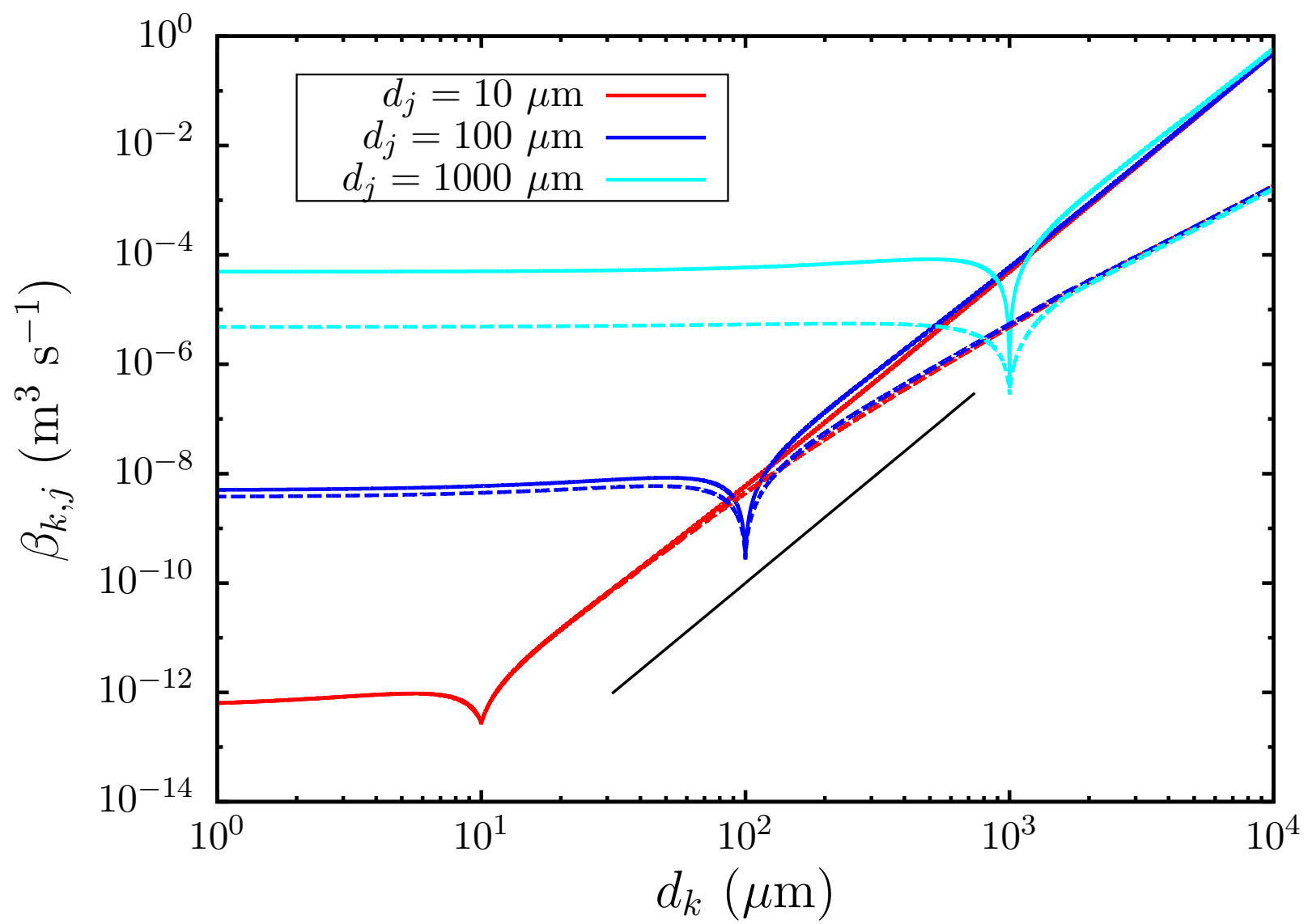

Figure 4. The variation in the collision rate $\left(\beta_{k, j}\right)$ with $d_{k}$ for three values of $d_{j}$ : the solid lines are calculated with Stokes terminal velocity and the dashed lines are calculated with the terminal velocity given by Eqs (28)-(30). The black line is proportional to $d_{k}^{4}$.

and that this difference increases as $d_{j}$ increases in magnitude. This explains the kink in Figure 4 when $d_{k}=d_{j}$ and why it becomes sharper as $d_{j}$ increases.

For $d_{k} \gg d_{j}$ scale analysis shows that

$\beta_{k, j} \approx \mathcal{B} \frac{d_{k}}{d_{j}}+\mathcal{S} d_{k}^{4}$

For $d_{j} \in\left[1,10^{4}\right] \mu \mathrm{m}$ and $d_{k} \gg d_{j}$, the second term dominates. Thus, to leading order $\beta_{k, j} \propto d_{k}^{4}$ for $d_{k} \gg d_{j}$ which is consistent with what is observed in Figure 4 when $\beta_{k, j}$ is computed with Stokes' terminal velocity or for $d_{k}$ not too large when $\beta_{k, j}$ is computed with the terminal velocity given by Eqs (28)-(30).

$S t_{v}=V\left|d_{j}-d_{k}\right| d_{j} d_{k}+\frac{B}{d_{j}+d_{k}}+S d_{j} d_{k}$ 
where

$V=\frac{4 g \rho_{s}^{2}}{81 \mu_{l} \mu_{a}} \quad B=\frac{64 \rho_{s} k_{B} T}{27 \pi \mu_{l} \mu_{a}} \quad S=\frac{4 \rho_{s}}{9 \pi \mu_{l}}\left(\frac{1.7 \epsilon}{\nu_{a}}\right)^{1 / 2}$

are assumed to be constant and we have also assumed that the two colliding particles have the same density (as in Section 3).

Using the same values of the parameters as above (with constant $\rho_{s}$ ), the constants have the following orders of magnitude:

$V \sim 10^{14} \quad \mathrm{~m}^{-3} \quad B \sim 10^{-10} \quad \mathrm{~m}^{-1} \quad S \sim 10^{7} \quad \mathrm{~m}^{-2}$

Note that $S t_{v}$ and hence $\alpha_{k, j}$ are symmetric in the indices $k$ and $j$.

Consider first the special case $d_{k}=d_{j}$. Then Eq. 45 becomes

$S t_{v}=\frac{B}{2 d_{j}}+S d_{j}^{2}$

310 The first term dominates for $d_{j} \lesssim 1 \mu \mathrm{m}$; the second term dominates for $d_{j} \gtrsim 10 \mu \mathrm{m}$. For $d_{j} \lesssim 1000 \mu \mathrm{m}, S t_{v} \lesssim S t_{c r}$ and so

$\alpha \approx 1-\left(\frac{S t_{v}}{S t_{c r}}\right)^{q} \approx 1$

whereas for $d_{j} \gtrsim 1000 \mu \mathrm{m}, S t_{v} \gtrsim S t_{c r}$ and so

$\alpha \approx \frac{S t_{c r}^{q}}{S t_{v}^{q}}\left(1-\left(\frac{S t_{c r}}{S t_{v}}\right)^{q}\right) \lesssim 1$

In the case $d_{k} \ll d_{j}$ Eq. 45 becomes

$S t_{v}=V d_{j}^{2} d_{k}+\frac{B}{d_{j}}+S d_{j} d_{k}$

Again we fix $d_{j}$ and allow $d_{k}$ to vary. The smallest admissible values of $d_{j}$ and $d_{k}$ that are in the range $[1,10000] \mu \mathrm{m}$ are $d_{j} \sim 10 \mu \mathrm{m}$ and $d_{k} \sim 1 \mu \mathrm{m}$; for these values a scale analysis shows that the first term on the rhs is dominant. For $d_{j} \sim 10^{4} \mu \mathrm{m}$, the largest admissible value, and $d_{k} \in[1,1000] \mu \mathrm{m}$ a scale analysis also shows that the first term on the rhs is dominant. Thus, Eq. 37 becomes

$\alpha_{k, j} \approx\left(\frac{S t_{c r}}{V d_{j}^{2} d_{k}}\right)^{q}\left(1-\left(\frac{S t_{c r}}{V d_{j}^{2} d_{k}}\right)^{q}\right)$

if $V d_{j}^{2} d_{k} / S t_{c r}>1$ whereas

$\alpha_{k, j} \approx 1-\left(\frac{V d_{j}^{2} d_{k}}{S t_{c r}}\right)^{q}$

if $V d_{j}^{2} d_{k} / S t_{c r}<1$. Since $S t_{c r}$ is always of order unity, if $V d_{j}^{2} d_{k} \ll 1$ then $\alpha \approx 1$. As $d_{j}$ increases the range of $d_{k}$-values for which $V d_{j}^{2} d_{k} \ll 1$ decreases. For $d_{j} \gtrsim 100 \mu$ m we see that $V d_{j}^{2} d_{k} \gtrsim 1$ for all admissible values of $d_{k}$.

In the case $d_{k} \gg d_{j}$ a similar scale analysis to that above shows that the first term on the rhs of Eq. 45 is again the dominant term; it now takes the form $V d_{k}^{2} d_{j}$. For $d_{j} \sim 1 \mu \mathrm{m}, V d_{k}^{2} d_{j} \gtrsim 1$ if $d_{k} \gtrsim 100 \mu \mathrm{m}$. For $d_{j} \sim 1000 \mu \mathrm{m}$ it follows from the condition 
https://doi.org/10.5194/acp-2021-254

Preprint. Discussion started: 31 May 2021

(c) Author(s) 2021. CC BY 4.0 License.
Atmospheric

Chemistry

and Physics

Discussions (a) $d_{j}=10 \mu \mathrm{m}$

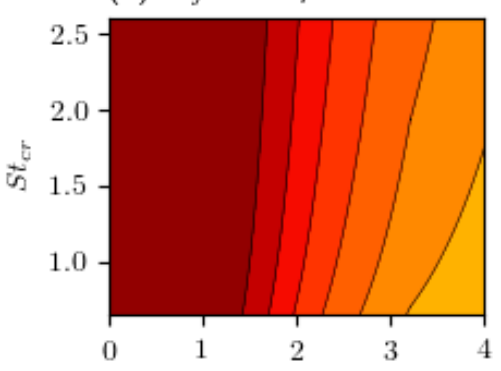

(d)

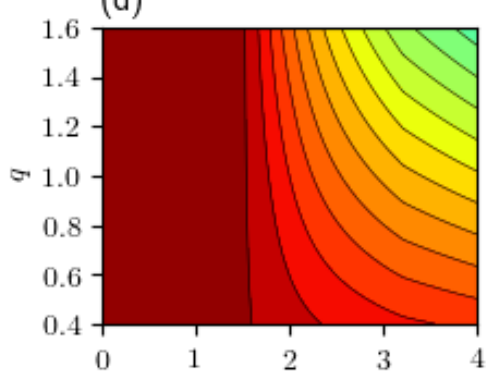

(g)

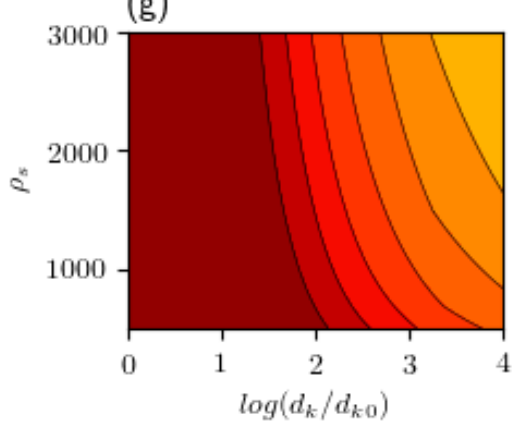

(b) $d_{j}=100 \mu \mathrm{m}$

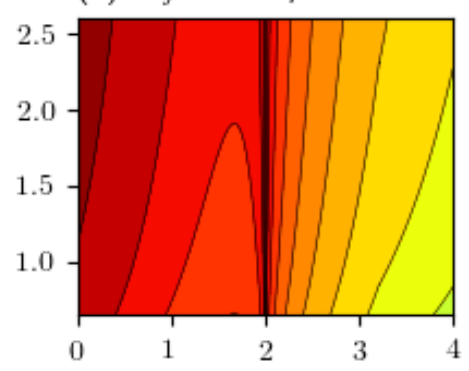

(e)

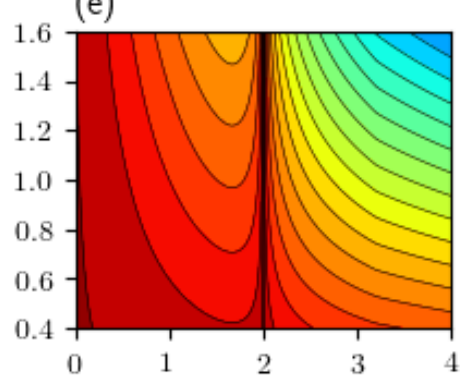

(h)

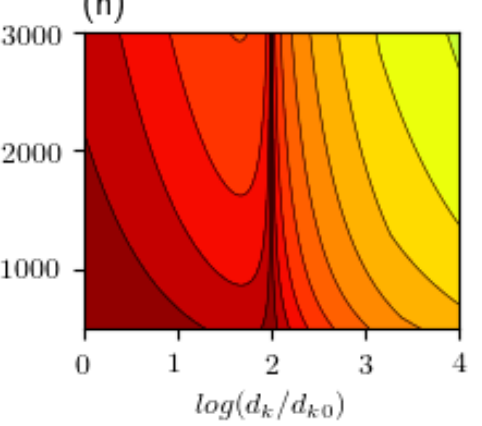

(c) $d_{j}=1000 \mu \mathrm{m}$
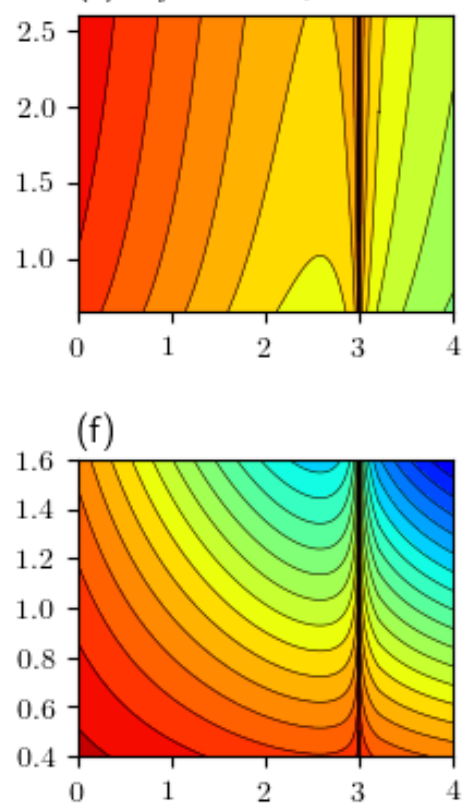

(i)

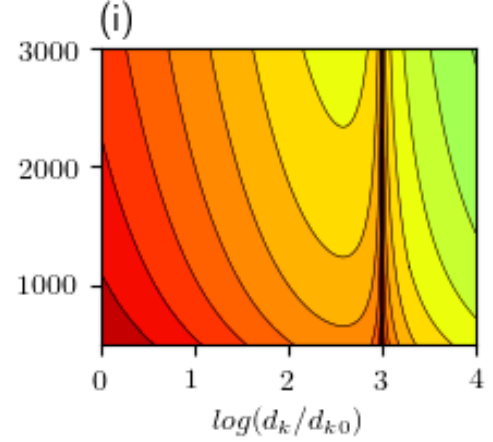

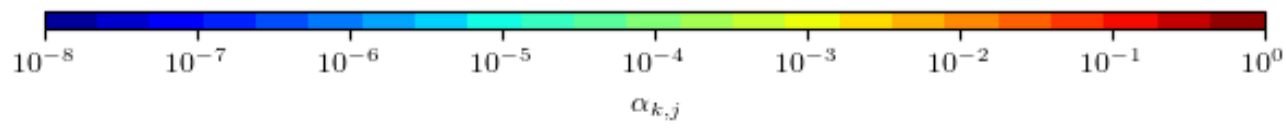

Figure 5. The variation in sticking efficiency $\left(\alpha_{k, j}\right)$ with $S t_{c r}$ (top row), $q$ (middle row) and $\rho_{s}$ (bottom row) for three fixed values of $d_{j}$ : $d_{j}=10 \mu \mathrm{m}$ (left column); $d_{j}=100 \mu \mathrm{m}$ (middle column); $d_{j}=1000 \mu \mathrm{m}$ (right column). The diameter $d_{k 0}=1 \mu \mathrm{m}$. 
$d_{k} \gg d_{j}$ that $d_{k} \sim 10^{4} \mu \mathrm{m}$ and so $V d_{k}^{2} d_{j} \gtrsim 1$ is always satisfied. For these values we would expect $\alpha<1$. As $d_{j}$ increases the range of $d_{k}$-values for which $V d_{k}^{2} d_{j} \gtrsim 1$ and $\alpha<1$ increases (e.g. if $d_{j} \sim 100 \mu \mathrm{m}$ then $d_{k} \gtrsim 10 \mu \mathrm{m}$ for $V d_{k}^{2} d_{j} \gtrsim 1$ to hold).

Figure 5 shows the variation of $\alpha_{k, j}$ with $S t_{c r}, q$ and $\rho_{s}$ computed with the terminal velocity given by Eqs (28)-(30). We start by considering the variation with $S t_{c r}$ : when $d_{j}=10 \mu \mathrm{m}$ (Figure 5a) then for both $d_{k}<d_{j}$ and $d_{k} \ngtr d_{j}$ it can be seen that $\alpha \approx 1$ as expected since here $V d_{j}^{2} d_{k} \ll 1$ and $V d_{k}^{2} d_{j} \ll 1$ for $d_{k} \gg 10 \mu \mathrm{m}$. For increasing $d_{k} \gg d_{j}$ we see $\alpha_{k, j}$ decreasing for all values of $S t_{c r}$ since here $V d_{k}^{2} d_{j} \gg 1$. For a given value of $d_{k} \gg d_{j}$, Figure 5a shows that $\alpha_{k, j}$ increases by approximately $4^{q}$ over the range of $S t_{c r}$ shown. A similar pattern can be seen for $d_{k} \gg d_{j}$ in Figures $5 \mathrm{~b}$ and c. Compared with Figure 5a, Figures $5 \mathrm{~b}$ and c show more variation with $S t_{c r}$ for $d_{k} \ll d_{j}$ and decreasing values of $\alpha_{k, j}$; this occurs because $V d_{j}^{2} d_{k}$ increases with increasing $d_{j}$ and of course the range of $d_{k}$-values satisfying $d_{k} \ll d_{j}$ also increases with increasing $d_{j}$. Turning now to the variation of $\alpha_{k, j}$ with $q$ in Figures 5d-f, it can be seen that, while the variation with $d_{k}$ for different (fixed) values of $d_{j}$ is similar to that in Figures 5a-c, there is much more variation of $\alpha_{k, j}$ with $q$ compared with $S t_{c r}$. Because $q$ appears in $\alpha_{k, j}$ as an exponent, a change in the value of $q$ is not simply a multiplicative change as it is with a change in the value of $S t_{c r}$. Raising $V d_{k}^{2} d_{j}>1$ to the power $q>1$ will enhance its value whereas raising it to the power $q<1$ will diminish its value; similarly for $V d_{j}^{2} d_{k}$. Thus, for example, as shown in Figure $5 \mathrm{~d}$ when $d_{j}=10 \mu \mathrm{m}$ and $d_{k} \gg d_{j}, V d_{k}^{2} d_{j}>1$ for $d_{k} \gtrsim 10^{-4} \mathrm{~m}$ and so, for $q>1, \alpha_{k, j}$ is smaller than it would be for $q=1$ whereas for $q<1$ is is larger. These patterns hold true in Figures $5 \mathrm{e}$ and $\mathrm{f}$ for $d_{k} \gg d_{j}$ though with diminishing values of $\alpha_{k, j}$ for increasing values of $d_{j}$. Similarly, we see in Figure 5f, for example, that, for $d_{k} \ll d_{j}, V d_{j}^{2} d_{k}>1$ for all values of $d_{k} \in[1,100] \mu \mathrm{m}$ and so $\alpha_{k, j}$ is closer to unity for $q<1$ and vice-versa for $q>1$.

345 The assumption of constant $\rho_{s}$ in the analysis above can be relaxed. We then see that $\beta_{k, j}$ depends linearly on $\rho_{s}$ except when $d_{k}=d_{j}$ (when $\beta_{k, j}$ is independent of $\rho_{s}$ ). The sticking efficiency also depends on $\rho_{s}$ : to leading order $S t_{v}$ varies like $\rho_{s}^{2}$ and so $\alpha_{k, j}$ decreases with increasing $\rho_{s}$. Figures 5g-i show the variation of $\alpha_{k, j}$ over the range of $\rho_{s}$-values considered in Section 3. There is more variation of $\alpha_{k, j}$ with $\rho_{s}$ compared with the variation of $\alpha_{k, j}$ with $S t_{c r}$ (for fixed $q$ and $\rho_{s}$ ) over the range of $S t_{c r}$-values shown in Figures 5a-c.

Figure 6 shows the variation of the collision kernel, $K_{k, j}=\alpha_{k, j} \beta_{k, j}$ (Eq. 22), with $S t_{c r}, q$ and $\rho_{s}$ computed with the terminal velocity given by Eqs (28)-(30). It is immediately clear that while the sticking efficiency tends to be largest for the particles with the smallest diameters this is negated by the relatively small values of the collision rate for particles of the same size. The net effect is that the largest values of the collision kernel tend to be found for the particles with the largest diameters. The largest range of values occurs for the smallest value of $d_{j}$ and vice-versa. This reflects the dominance of differential settling in the collision kernel.

It should be noted that $\alpha_{k, j}$ computed with Stokes' terminal velocity shows a larger variation than that shown in Figure 5. Since Stokes' terminal velocity is larger than that calculated from Eqs (28)-(30) for large diameters and $\alpha_{k, j}$ is dominated by differential settling, then for large diameters $\alpha_{k, j}$ becomes smaller than the values shown in Figure 5. Conversely Figure 4 shows that $\beta_{k, j}$ is larger when using Stokes' terminal velocity. The net effect is that the collision kernel computed with Stokes' terminal velocity is similar in magnitude to that shown in Figure 6. 
https://doi.org/10.5194/acp-2021-254

Preprint. Discussion started: 31 May 2021

(c) Author(s) 2021. CC BY 4.0 License.
Atmospheric

Chemistry and Physics

Discussions (a) $d_{j}=10 \mu \mathrm{m}$

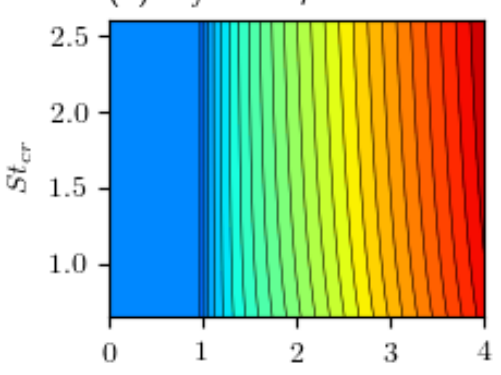

(d)

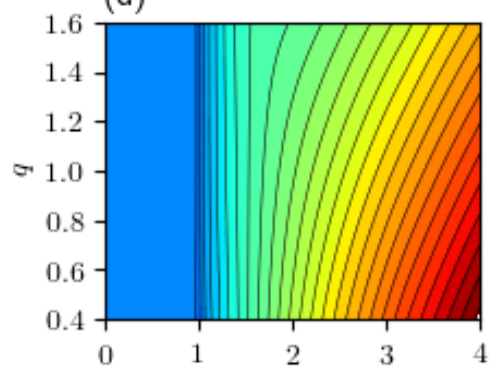

(g)

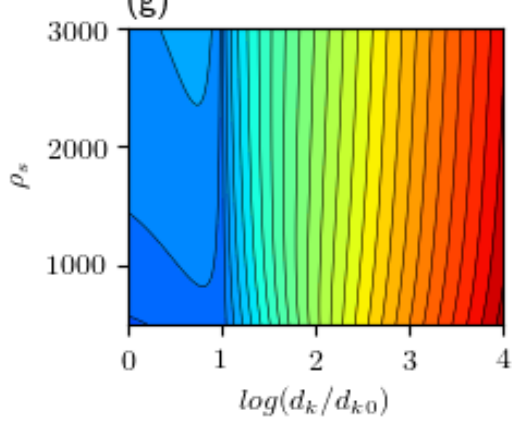

(b) $d_{j}=100 \mu \mathrm{m}$

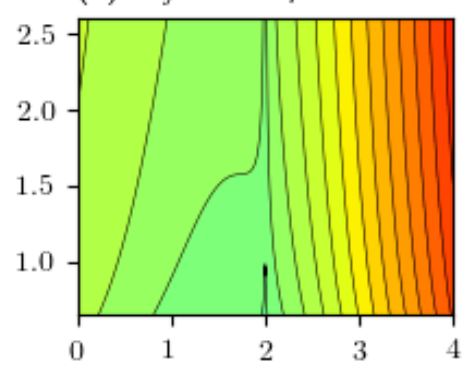

(e)

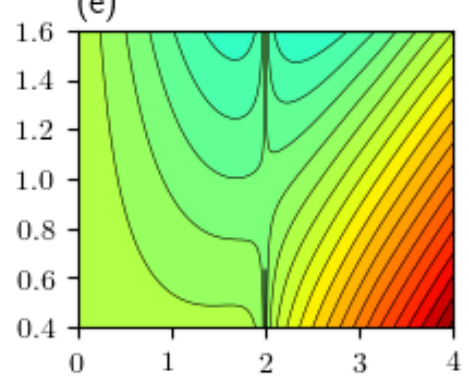

(h)

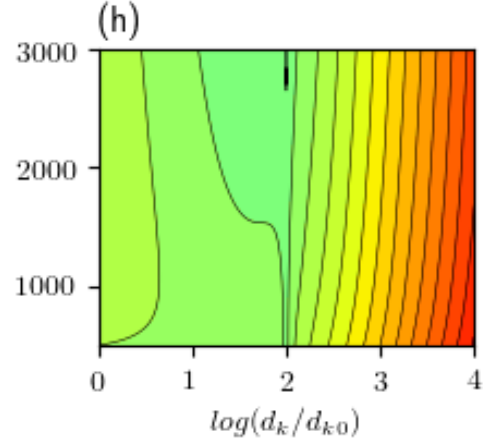

(c) $d_{j}=1000 \mu \mathrm{m}$
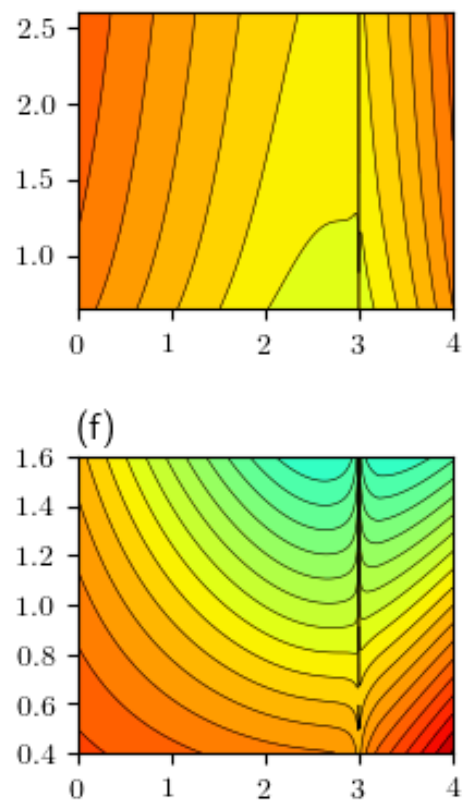

(i)

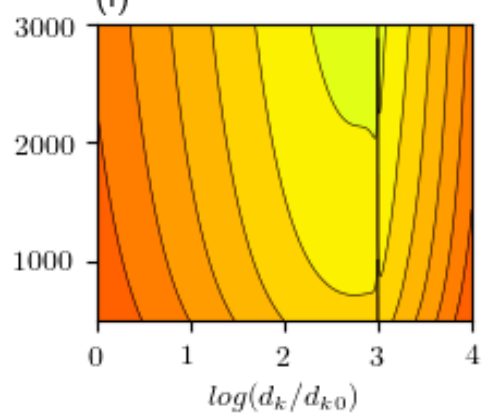

$$
10^{-14}
$$

$10^{-12}$

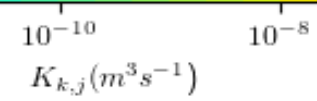

$10^{-6}$

Figure 6. The variation in the collision kernel $\left(K_{k, j}\right)$ with $S t_{c r}$ (top row), $q$ (middle row) and $\rho_{s}$ (bottom row) for three fixed values of $d_{j}$ : $d_{j}=10 \mu \mathrm{m}$ (left column); $d_{j}=100 \mu \mathrm{m}$ (middle column); $d_{j}=1000 \mu \mathrm{m}$ (right column). The diameter $d_{k 0}=1 \mu \mathrm{m}$. 
Figure 6 shows that the variation of $K_{k, j}$ with $S t_{c r}$ (over the range of values shown in Figures 6a-c) is smaller than the variation of $K_{k, j}$ with $\rho_{s}$ (Figures $6 \mathrm{~g}-\mathrm{i}$ ) and that both of these are smaller than the variation of $K_{k, j}$ with $q$ (Figures 6d-f). For a given value of $d_{k}$, the value of $K_{k, j}$ increases with increasing $S t_{c r}$ but decreases with increasing $\rho_{s}$. Figures $6 \mathrm{~d}-\mathrm{f}$ show that the variation with $q$ is more complicated but the largest values of $K_{k, j}$ occur for the smallest values of $q$ (for a given value of $d_{k}$ ). This explains why the mode of the AGSD in Figure 3 shifts to larger diameters with increasing $S t_{c r}$, decreasing $q$ or $\rho_{s}$. The behaviour of $\alpha_{k, j}, \beta_{k, j}$ and its product, $K_{k, j}$ with respect to changes in $S t_{c r}, q$ and $\rho_{s}$ explains why there is less variation of the AGSD with $S t_{c r}$ compared with $q$ and $\rho_{s}$. However, this behaviour cannot explain all the variation of the AGSD with $\rho_{s}$ which is much larger than that with either $S t_{c r}$ or $q$. The additional factor is explained by Eq. 21 which shows that the particle number density for a given size bin, $N_{i}$, increases with decreasing $\rho_{s}$ since $m_{i}$ is proportional to $\rho_{s}$.

\section{Dispersion Modelling}

We investigate the impact of representing aggregation on dispersion model simulations of the distal ash cloud from the eruption of Eyjafjallajökull volcano in 2010. We consider the period between the 04/05/2010 - 08/05/2010, as we have measurements of the GSD and density of the non-aggregated grains sampled from deposits for this time (Bonadonna et al., 2011). The aggregation scheme is coupled to NAME, such that NAME uses the output AGSD at the top of the plume and Mass Eruption Rate (MER) calculated from the buoyant plume scheme initialised with the observed plume heights, at every time step. The aggregation scheme is initialized with the measured GSD of the non-aggregated ash (see Figure 3d). However, in the initialization of NAME we consider only grains which have a diameter of $\leq 125 \mu \mathrm{m}$ and take just $5 \%$ of the total MER to represent the mass in the distal ash cloud, following the approach of the London VAAC (Beckett et al., 2020). Figure 7 shows an example of the output AGSD normalized to $125 \mu \mathrm{m}$. It is compared to the input size distribution of the non-aggregated grains. Mass has been lost from grains with diameter $\leq 16 \mu \mathrm{m}$, however the mode of the normalized distributions are the same, lying at $64-125$ $\mu \mathrm{m}$. The density distribution of the non-aggregated grains is also shown; densities range from $2039-2738 \mathrm{~kg} \mathrm{~m}^{-3}$ for this size range (Bonadonna and Phillips, 2003; Bonadonna et al., 2011). Model particles are released with a uniform distribution over the depth of the modelled (bent-over) plume (Devenish, 2013, 2016). The setup of the NAME runs is given in Table 5 and we use the control internal model parameters in the aggregation scheme (Table 3).

Figure 8a shows the modelled 1-hour averaged total column mass loadings in the ash cloud at 00:00 on the 05/05/2010, 24 hours after the release start, using the measured GSD (normalized to $125 \mu \mathrm{m}$ ) and density distribution of the non-aggregated Eyjafjallajökull ash. In comparison Figure 8b shows the modelled plume using the normalized time-varying AGSD. As the density of the Eyjafjallajökull aggregates is not known the measured density distribution of the single grains is applied. Current regulations in Europe state that airlines must have a safety case accepted in order to operate in ash concentrations greater than $2 \times 10^{-3} \mathrm{~g} \mathrm{~m}^{-3}$. We assume a cloud depth of $1 \mathrm{~km}$ and consider the area of the ash cloud with mass loadings $>2 \mathrm{~g} \mathrm{~m}^{-2}$ to compare the differences in the modelled areas which are significant for aircraft operations. Using the aggregated GSD the extent of the ash cloud is only slightly smaller, it is reduced by just $\sim 3 \%$, reflecting the slight increase in the fraction of larger (aggregated) grains in the ash cloud which have a greater fall velocity and hence shorter residence time in the atmosphere. 
However, it is expected that porous aggregates, specifically cored clusters (PC3, see Brown et al. (2012) and Bagheri et al. (2016) for topology definitions) may have lower densities than single grains of ash of equivalent size (Bagheri et al., 2016; Gabellini et al., 2020; Rossi et al., 2021). Figure 9 shows the modelled ash cloud when we assume that the aggregates have densities of 1000 and $500 \mathrm{~kg} \mathrm{~m}^{-3}$ (Taddeucci et al., 2011; Gabellini et al., 2020; Rossi et al., 2021). As the aggregation scheme does not track explicitly the mass fraction of aggregates versus single grains we must also make an assumption about how much of the mass released is represented by aggregates with the lower density. Here we consider the case where 25,50 and $75 \%$ of the total mass on the ash $\leq 125 \mu \mathrm{m}$ is represented by aggregates. Assigning a lower density to the aggregates reduces their fall velocity and the extent of the simulated ash cloud increases: if we assume that $75 \%$ of the mass of ash $\leq 125 \mu \mathrm{m}$ is represented by aggregates, when they are assigned a density of $1000 \mathrm{~kg} \mathrm{~m}^{-3}$ the simulated ash cloud with mass loadings $>$ $2 \mathrm{~g} \mathrm{~m}^{-2}$ is $32,042 \mathrm{~km}^{2}$, this increases to $34,697 \mathrm{~km}^{2}$ when they are assigned a density of $500 \mathrm{~kg} \mathrm{~m}^{-3}$. Figure 10 shows the relative increase in the area of the ash cloud with concentrations $>2 \mathrm{~g} \mathrm{~m}^{-2}$ as a function of the mass fraction of aggregates in

405 the ash cloud and their density. The circle with a diameter of 1 represents the extent of the modelled cloud when aggregation is not considered (area 29,278 $\mathrm{km}^{2}$ ). The largest modelled ash cloud is $\sim 1.2$ times bigger. This is achieved when we use the AGSD, assign the aggregates a density of $500 \mathrm{~kg} \mathrm{~m}^{-3}$, and assume that aggregates constitute $75 \%$ of the total mass released in NAME (ash $\leq 125 \mu \mathrm{m})$.

Table 5. Input parameters for the NAME runs.

\begin{tabular}{l|l} 
Model Parameter & Value \\
\hline Source Location & Eyjafjallajökull, $63.63^{\circ}$ lat, $-19.62^{\circ}$ lon \\
Summit height & $1666 \mathrm{~m}$ asl \\
Source Start + End Times & $00: 0004 / 05 / 2010-23: 0008 / 05 / 2010$ \\
Source Shape & Line source, using depth of the modelled plume, uniform distribution \\
Source Strength & From buoyant plume scheme, given the observed plume height \\
Model Particle Release Rate & $15,000 \mathrm{hr}^{-1}$ \\
Particle Shape & Spherical \\
GSD & Set by the aggregation scheme \\
Meterological data & Unified Model (Global configuration): $\sim 25$ km horizontal resolution (mid-latitudes) \\
& 3 hourly temporal resolution \\
Time Step & 10 minutes
\end{tabular}




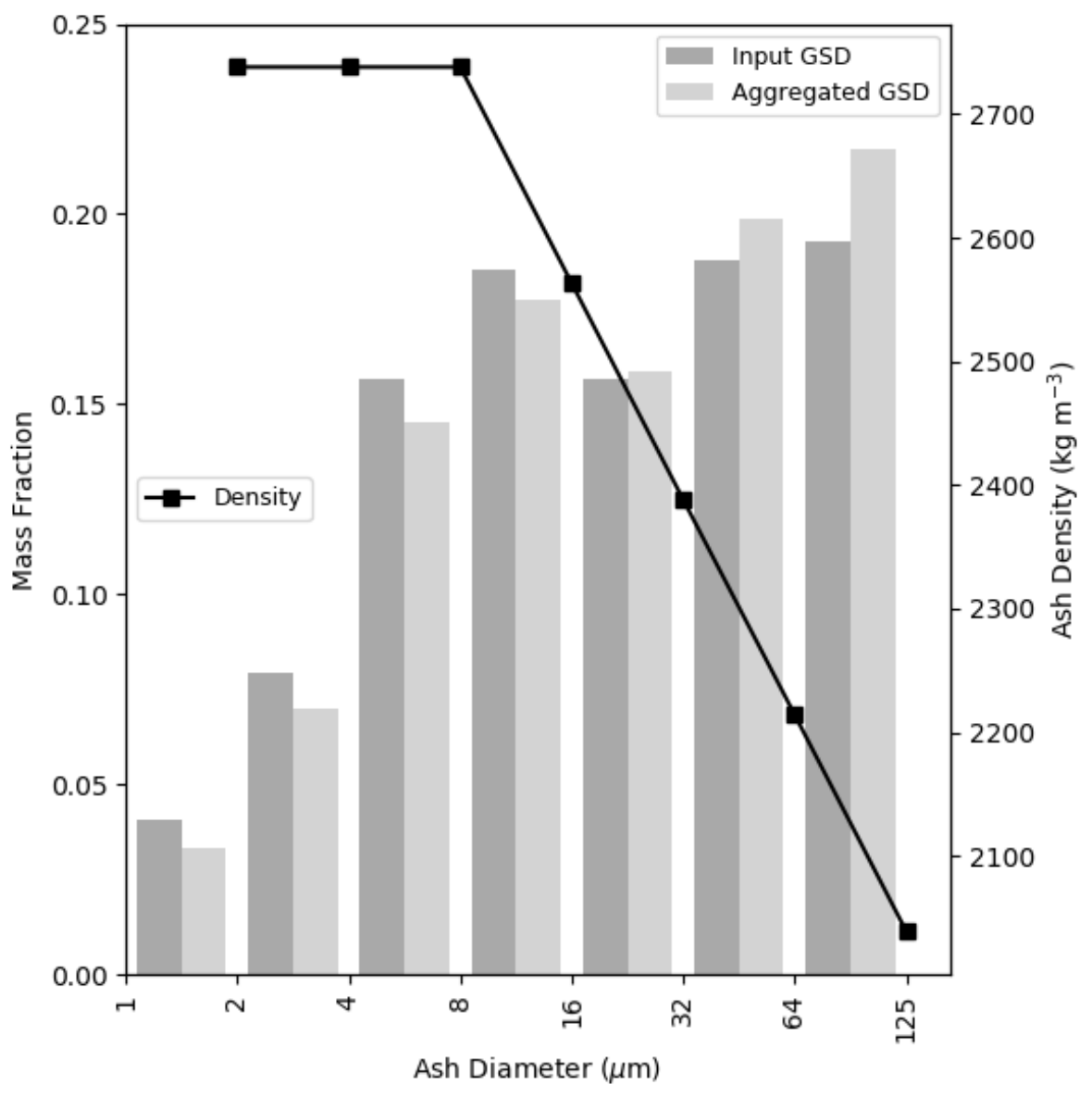

Figure 7. Normalized $(d \leq 125 \mu \mathrm{m})$ GSDs of the Eyjafjallajökull 2010 non-aggregated ash measured from deposits (dark grey bars, from Bonadonna et al. (2011)) and the modelled aggregated ash at the top of the plume (light grey bars), at 19:00 UTC on the 04/05/2010. The density distribution of the single non-aggregated ash grains from deposits (taken from Bonadonna et al. (2011) using the method of Bonadonna and Phillips (2003)) is also shown. 
https://doi.org/10.5194/acp-2021-254

Preprint. Discussion started: 31 May 2021

(c) Author(s) 2021. CC BY 4.0 License.

(c) (i)

(a)

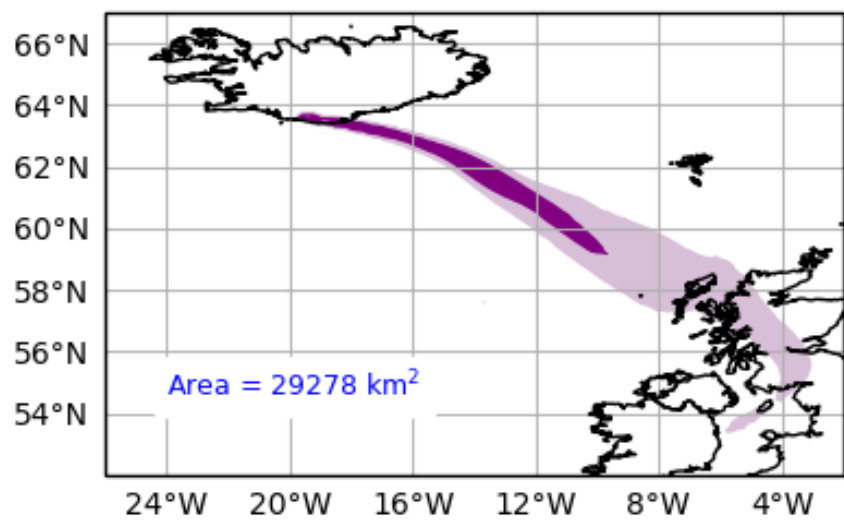

(b)

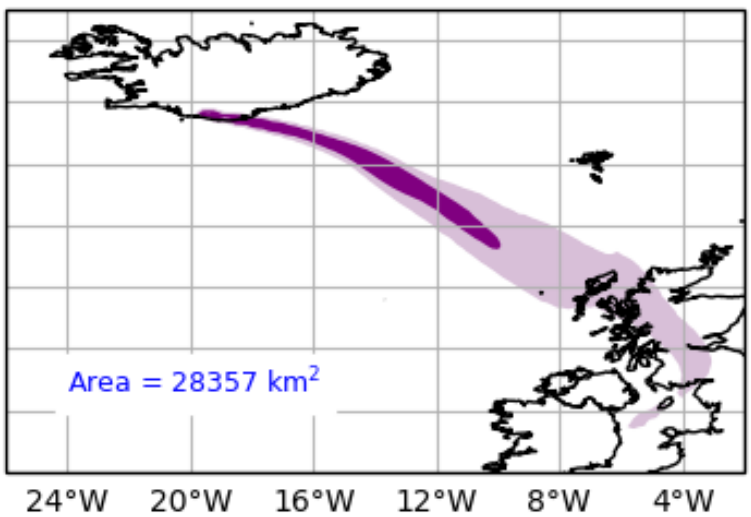

$24^{\circ} \mathrm{W} \quad 20^{\circ} \mathrm{W} \quad 16^{\circ} \mathrm{W} \quad 12^{\circ} \mathrm{W} \quad 8^{\circ} \mathrm{W} \quad 4^{\circ} \mathrm{W}$

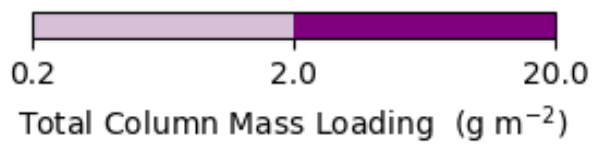

Figure 8. Modelled 1-hour averaged total column mass loadings of the Eyjafjallajökull ash cloud at 00:00 UTC on the 05/05/2010 using (a) the measured GSD of the non-aggregated ash, (b) the time-varying aggregated GSD. The measured density distribution of the non-aggregated ash grains is applied in both cases. The area of the ash cloud with mass loadings $>2 \mathrm{~g} \mathrm{~m}^{-2}$, which is significant for aircraft operations, is shown. 
$1000 \mathrm{~kg} \mathrm{~m}^{-3}$
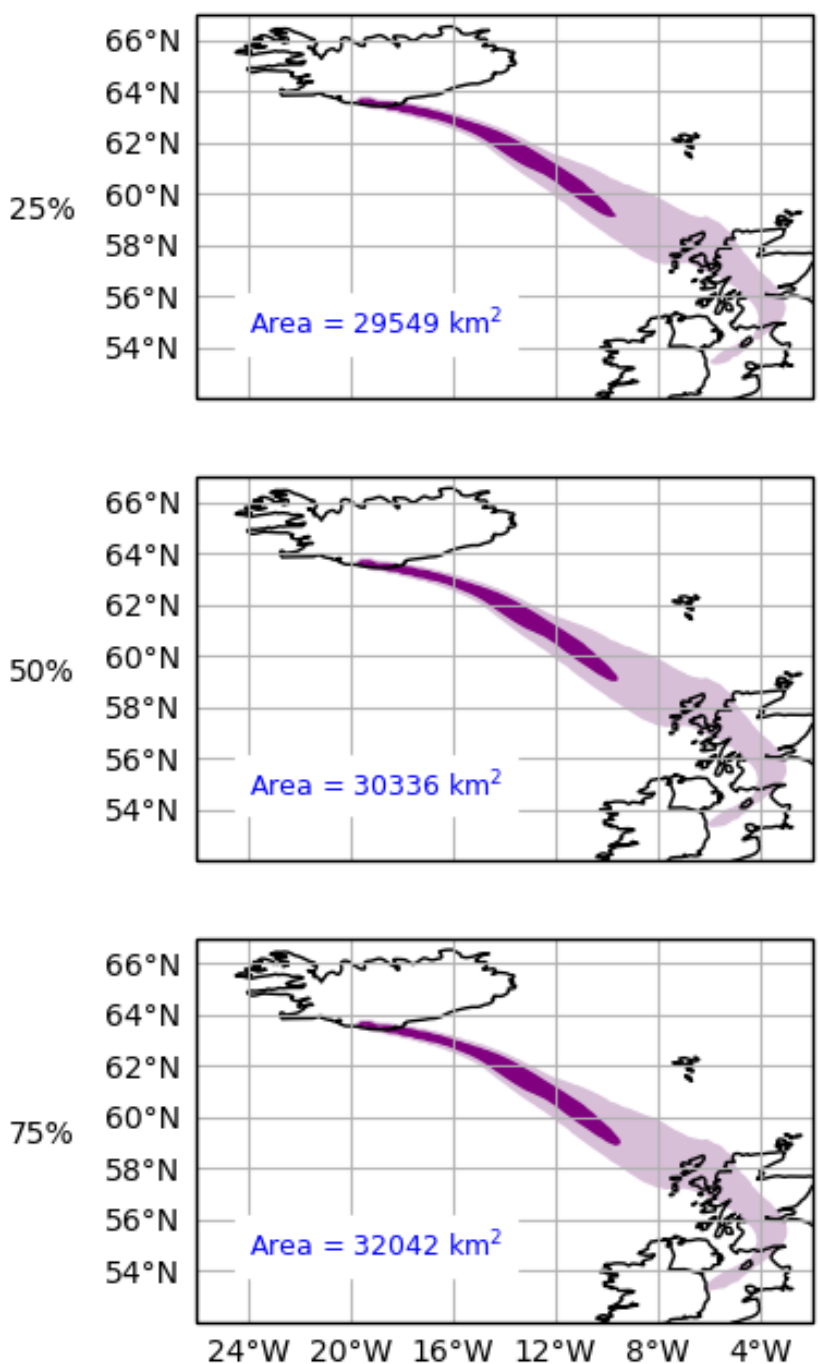

$500 \mathrm{~kg} \mathrm{~m}^{-3}$
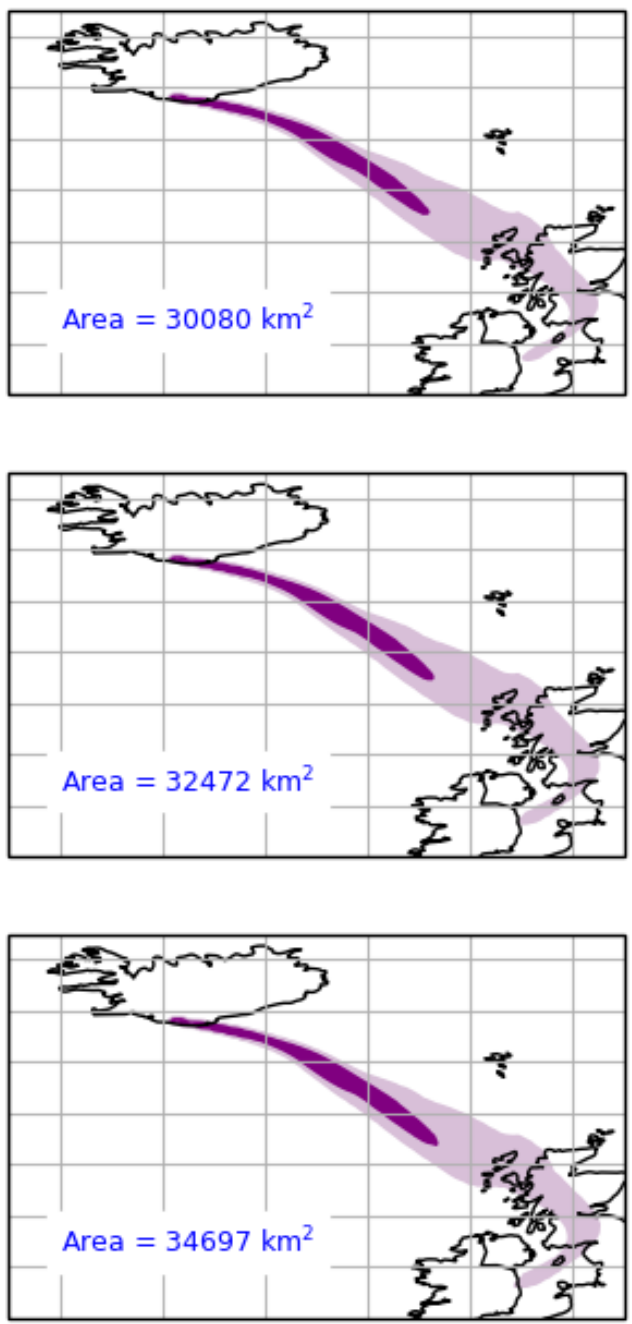

$24^{\circ} \mathrm{W} \quad 20^{\circ} \mathrm{W} \quad 16^{\circ} \mathrm{W} \quad 12^{\circ} \mathrm{W} \quad 8^{\circ} \mathrm{W} \quad 4^{\circ} \mathrm{W}$

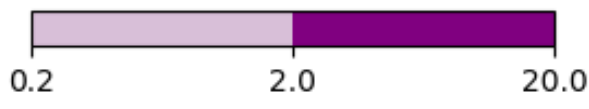

Total Column Mass Loading $\left(\mathrm{g} \mathrm{m}^{-2}\right)$

Figure 9. Modelled 1-hour averaged total column mass loadings of the Eyjafjallajökull ash cloud at 00:00 UTC on the 05/05/2010 when $25 \%, 50 \%$ and $75 \%$ of the mass is on aggregates with density $1000 \mathrm{~kg} \mathrm{~m}^{-3}$ and $500 \mathrm{~kg} \mathrm{~m}^{-3}$. The area of the ash cloud with mass loadings $>2 \mathrm{~g} \mathrm{~m}^{-2}$, which is significant for aircraft operations, is shown. 
https://doi.org/10.5194/acp-2021-254

Preprint. Discussion started: 31 May 2021

(c) Author(s) 2021. CC BY 4.0 License.

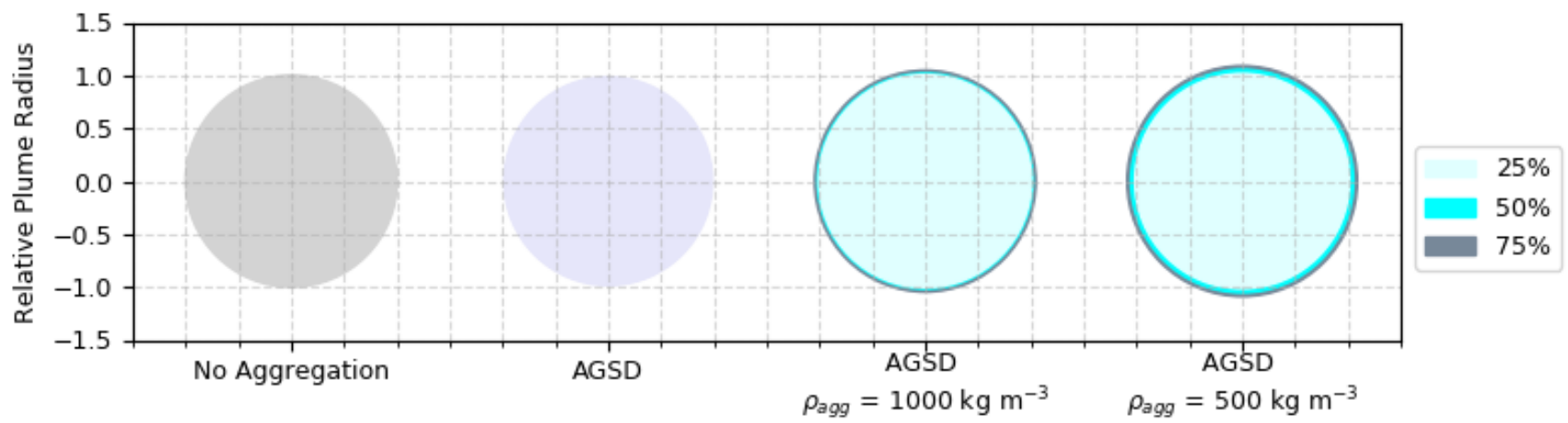

Figure 10. Relative areas of the Eyjafjallajökull ash cloud with concentrations $>2 \mathrm{~g} \mathrm{~m}^{-2}$ at 00:00 UTC on the 05/05/2010. The area of the ash cloud when aggregation is not considered has a relative radius of 1 . The modelled areas using AGSDs when 25, 50 and 75\% of the mass released is assumed to be on aggregates with a density of $1000 \mathrm{~kg} \mathrm{~m}^{-3}$ and $500 \mathrm{~kg} \mathrm{~m}^{-3}$ are compared. 


\section{Discussion}

410 We have integrated an aggregation scheme into the atmospheric dispersion model NAME. The scheme is coupled to a one dimensional buoyant plume model and uses the FPT to solve the SCE to simulate aggregation processes in an eruption column. The time-evolving AGSD at the top of the plume is provided to NAME as part of the source conditions. This represents the first attempt at modelling explicitly the change in the GSD of the ash due to aggregation in a model which is used for operational response, as opposed to assuming a single aggregate class (Cornell et al., 1983; Bonadonna et al., 2002; Costa et al., 2010). Our scheme predicts that mass is preferentially removed from bins representing the smallest ash $(\leq 64 \mu \mathrm{m})$. This agrees well with field and laboratory experiments which have also observed that aggregates mainly consist of particles $<63 \mu$ m in diameter (Bonadonna et al., 2011; James et al., 2002, 2003). This suggests aggregation will be more prevalent when large quantities of fine ash are generated by the eruption.

Previous sensitivity studies of dispersion model simulations of volcanic ash clouds have highlighted the importance of constraining the GSD of ash for operational forecasts, as this parameter strongly influences its residence time in the atmosphere (Scollo et al., 2008; Beckett et al., 2015; Durant, 2015; Poret et al., 2017; Osman et al., 2020; Poulidis and Iguchi, 2020). Here we show that the modelled AGSD is also sensitive to the GSD, and the density, of the non-aggregated ash at the source. When the scheme is initialized with a coarse GSD there are fewer particles per unit volume (lower number concentrations) within the plume and aggregation is reduced. Whereas when particle densities are low, for the same mass flux, there are higher number concentrations and hence more aggregation.

Dispersion model simulations are influenced by the interplay between the size and density distributions of the aggregated ash. Aggregates can have higher fall velocities than the smaller single grains of which they are composed, and therefore act to reduce the extent and concentration of ash in the atmosphere (Rossi et al., 2021). However, porous aggregates can also have lower densities than the single grains, and this can act to 'raft' ash to much greater distances (Bagheri et al., 2016; Rossi et al., 2021). In our case study of the Eyjafjallajökull 2010 eruption we found that although mass was lost from bins representing smaller grain sizes the mode of the AGSD did not differ from the source GSD of the erupted non-aggregated ash, for example the output AGSD at 19:00 04/05/2010 has lost mass from ash $\leq 16 \mu \mathrm{m}$ but the mode remains at 64-125 $\mu \mathrm{m}$ (Figure 7). As such, we found that using the time-varying AGSD to initialise our dispersion model, rather than the size distribution of the single grains, had little impact on the simulated ash cloud. When we considered that aggregates may have (lower) densities of 1000 and $500 \mathrm{~kg} \mathrm{~m}^{-3}$ and make up $25-75 \%$ of the total mass of the simulated AGSD we found that the area of the ash cloud with concentrations significant for aircraft operations $\left(>2 \mathrm{~g} \mathrm{~m}^{-2}\right)$ varied by a factor of just $\sim 1.2$.

Previous studies which have considered the sensitivity of dispersion model forecasts of volcanic ash clouds to the density distribution of the ash have also suggested that simulations are relatively insensitive to this parameter (Scollo et al., 2008; Beckett et al., 2015). In fact, in this case, the modelled ash cloud is more sensitive to the input GSD of the non-aggregated ash at the source, than due to any change to the GSD or density of the ash due to aggregation. Osman et al. (2020) compared NAME simulations initialised with the default GSD used by the London VAAC (which is relatively fine) and the published GSD of 
ash from the 1991 eruption of Hekla which is much coarser. They found that simulations of the extent of the Eyjafjallajökull 2010 ash cloud with concentrations $>2 \mathrm{~g} \mathrm{~m}^{-2}$ varied by a factor of $\sim 2.5$.

It should be remembered that operational forecasts are also sensitive to other eruption source parameters needed to initialize dispersion model simulations. Dioguardi et al. (2020) found that given the uncertainty on the MER, forecasts of the area of the Eyjafjallajökull ash cloud with concentrations $>2 \times 10^{-3} \mathrm{~g} \mathrm{~m}^{-3}$ varied by a factor of 5 . When generating operational forecasts, uncertainty on the plume height, vertical distribution, MER and GSD of the non-aggregated ash at the source could therefore outweigh any error associated with not representing aggregation processes.

In the operational application of atmospheric dispersion models at VAACs it is often assumed that a large fraction of the total erupted mass is deposited close to the source. Only ash with diameters $\leq 100 \mu \mathrm{m}$ are considered by the London VAAC in their forecasts of the long-range transport of ash clouds (Beckett et al., 2020). Bonadonna et al. (2011) constrained the GSD of the ash from the 2010 eruption of Eyjafjallajökull volcano using ground sampling and satellite retrievals. They suggest that $41 \%$ of the total mass of erupted tephra was represented by grains with a diameter of $\leq 125 \mu \mathrm{m}$. Ash of this size can travel significant distances; > $700 \mathrm{~km}$ given the plume heights and meteorological conditions during the Eyjafjallajökull eruption (Beckett et al., 2015). However, measured ash concentrations over the UK, North Sea and North Atlantic made by research aircraft, groundbased lidar and satellite retrievals suggest that only $\sim 5 \%$ of the total erupted mass was actually present in the distal ash cloud (Devenish et al., 2012a, b; Dacre et al., 2011). Satellite measurements of the mass loading in ash clouds from El Chichón, Láscar, and Hudson volcanoes (Rose et al., 2000) also suggest that the distal fine ash fraction is just 5\%. It has been assumed that aggregation, which can enhance the removal of fine ash, might explain the discrepancy between the observed mass on small grains at the source and the relatively small fraction which makes it into the distal ash cloud. Aggregates, up to $600 \mu \mathrm{m}$ in diameter, composed of grains $<63 \mu \mathrm{m}$, were observed in Iceland during the Eyjafjallajökull eruption (Bonadonna et al., 2011). However, our simulated AGSD still has $\sim 30 \%$ of the total mass on tephra (aggregates and single grains) with diameters $\leq 125$ $\mu \mathrm{m}$, which, given their size and density, would travel further than Iceland before depositing due to sedimentation alone. Below we consider the limitations of our aggregation scheme. Alternatively, other near-source processes which act to prematurely remove ash from the ash cloud, such as gravitational instabilities (Carazzo and Jellinek, 2012; Durant, 2015; Manzella et al., 2015), hydrometeor formation (Durant and Rose, 2009; Durant et al., 2009), particle-particle interactions (Eychenne et al., 2015; Del Bello et al., 2017) and topography induced perturbations to local wind fields which can enhance sedimentation on the lee-side of mountains (Watt et al., 2015; Eychenne et al., 2017; Poulidis et al., 2017), could be playing a more dominant role. Or, the mass loading of fine ash in the distal ash cloud could be severely under-estimated by the current approaches, as postulated by Cashman and Rust (2019). Further work is needed to constrain the uncertainty on measured mass loadings and GSDs, associated with the methods used for both ground sampling (e.g. Bonadonna et al., 2015) and satellite retrievals (e.g. Stevenson et al., 2015). We would also benefit from further in situ measurements of the GSDs and densities of falling aggregates. 


\subsection{Limitations}

To be considerate of computational costs for operational systems we have limited aggregation processes to the eruption column only. However, it is likely that, while ash concentrations remain high, aggregation will continue in the dispersing ash cloud. As we do not represent electric fields in our scheme we are also unable to explicitly simulate aggregation through electrostatic attraction (Pollastri et al., 2021). Further work is needed to consider this contribution and the implications for the long-range transport of the ash cloud. Our approach may therefore underestimate the amount of aggregation, which could further shift the mode of the aggregated GSD to larger grain sizes. We also disregard disaggregation due to collisions with other aggregates and ash grains (Del Bello et al., 2015; Mueller et al., 2017). This process has received little attention and remains relatively under-constrained, and as such has also been neglected here.

Volcanic plumes are highly turbulent flows characterized by a wide range of interacting length and timescales. The length scale of the largest eddies (the integral scale) is the plume radius (e.g. Cerminara et al., 2016a). Whereas the smallest eddies are at the Kolmogorov scale, the point at which viscosity dominates and the turbulent kinetic energy is dissipated into heat. In the treatment of the collision kernels in our scheme we have assumed that the Saffman Turner limit is satisfied: that the particles are smaller than the smallest turbulent scale and as such are completely coupled with the flow. However, larger particles lie outside this limit and, if sufficiently large, will be uncorrelated with the flow. Further work is needed to consider the treatment of large uncorrelated particles, for example the application of the Abrahamson limit in the treatment of the collision kernels could be explored (Textor and Ernst, 2004).

We consider that particle sticking can occur due to viscous dissipation in the surface liquid layer on the ash (Liu et al., 2000; Liu and Litster, 2002). This is based on the assumption that large amounts of water (magmatic, ground water, and atmospheric) will be available, and the assumption that this mechanism will play a dominant role over other possible sticking mechanisms e.g. electrostatic forces (Costa et al., 2010). Using scaling analysis (Section 4) we show that the modelled AGSDs are particularly sensitive to the parameters used in the aggregation scheme to control the sticking efficiency of two colliding particles, the critical Stokes number ( $S t_{c r}$ ) and parameter $q$ (an exponent). Varying these parameters is in some sense equivalent to changing the amount of viscous dissipation acting on the surface of the particles, which is in turn related to the thickness of the surface water layers. Both of these parameters are poorly constrained and would benefit from further calibration with field and laboratory studies. In particular the depth of the liquid layers on ash grains needs to be better understood and applied here. The sticking efficiency also depends on the relative velocities between the colliding particles. In Eq. 34 we have neglected any effect of the particle inertia induced by the background turbulent flow which represents a further source of uncertainty.

Our 1-dimensional treatment of the SCE does not allow us to represent the change in density of the simulated aggregates, or track explicitly the mass fraction of aggregates versus single grains within a given size bin. Using their aggregation scheme in FPLUME Folch et al. (2016) predicted 10\% of the erupted mass from Eyjafjallajökull 2010 was represented by aggregates when column heights ranged from 6 to $7 \mathrm{~km}$ (agl) and 20\% for column heights between 7.2 and $8.3 \mathrm{~km}$ (agl). However, it should be remembered that these values are sensitive to the treatment of ambient conditions within their model (they assume aggregation only occurs in the presence of liquid water) and the fractal exponent they applied to describe the geometry of 
the aggregates. Our scheme could be significantly improved by using a multi-dimensional description which represents the fluctuation in the density of the growing aggregates and retains information on the mass fraction of aggregated particles. However, this would also require a better understanding of the structure (porosity) of aggregates.

We only consider aggregation due to the presence of water layers on the surface of the particles, following Costa et al. (2010). This approach could neglect the presence of particle clusters (PC), which usually require less water to form, and might therefore underestimate the impact of aggregation: it is suggested that $46 \%$ of the particles $<10 \mu \mathrm{m}$ fell as particle clusters during a field study of the Eyjafjallajökull ash cloud (Bonadonna et al., 2011). We assume that aggregation can occur for RH $>0 \%$, and scale the sticking efficiency by the RH. As the residence time in the presence of liquid water $(R H=1)$ increases more aggregation occurs, represented by a decrease in mass on smaller grains ( $m_{32}$ is reduced). If we were to consider that aggregation can only take place when liquid water is present in the modelled eruption column then, for the period considered in this study, aggregation would only occur in the top $\sim 1 \mathrm{~km}$, and in some instances no liquid water was formed (e.g. 13:00 06/05/2010 and 12:00 07/05/2010, Figure 1). Folch et al. (2010) found, using their 1-dimensional plume model, that there was only a $30 \mathrm{~s}$ window for ash to aggregate in the presence of liquid water in the initial phase of the eruption at Mount St Helen's in 1980, which generated a plume which rose $32 \mathrm{~km}$. For less vigorous plumes, like that generated from the eruption of Crater Peak 1992, despite the lower plume heights, they found that there was a longer, albeit still limited, time period ( $\sim 45 \mathrm{~s})$ for which liquid water was present. Further work is needed to better constrain the influence of the ambient conditions, such as the relative humidity, on liquid bonding of ash aggregates to improve simulations of their formation in volcanic ash clouds.

\section{Conclusions}

We have integrated an aggregation scheme into the atmospheric dispersion model NAME. The scheme uses an iterative buoyant plume model to simulate the eruption column dynamics and the Smoluchowski Coagulation Equations are solved with a sectional technique which allows us to simulate the AGSD in discrete bins. The modelled AGSD at the top of the eruption column is then used to represent the time-varying source conditions in the dispersion model simulations. Our scheme is based on the assumption that particle sticking is due to viscous dissipation of surface liquid layers on the ash, and scale analysis indicates that our output AGSD is strongly controlled by under-constrained parameters which attempt to represent these liquid layers. The modelled AGSD is also sensitive to the the physical characteristics assigned to the particles in the scheme: the initial GSD and density distribution. Our ability to accurately forecast the long range transport of volcanic ash clouds is, therefore, still limited by real-time information on the physical characteristics of the ash. We found that using the time-evolving AGSD in dispersion model simulations of the Eyjafjallajökull 2010 eruption had very little impact on the modelled extent of the distal ash cloud with mass loadings significant for aviation. However, our scheme does not represent all the possible mechanisms by which ash may aggregate (i.e. electrostatic forces), nor does it distinguish the density of the aggregated grains. Our results indicate the need for more field and laboratory experiments to further constrain the binding mechanisms and composition of aggregates; their size distribution and density. 
https://doi.org/10.5194/acp-2021-254

Preprint. Discussion started: 31 May 2021

(c) Author(s) 2021. CC BY 4.0 License.

(c) (i)

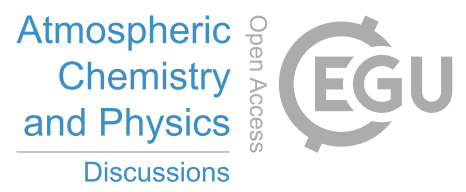

540 Code and data availability. Data used in this manuscript may be requested from the corresponding author and can be downloaded from https://doi.org/10.5281/zenodo.4607421. The NAME code is available under license from the Met Office.

Author contributions. FB performed the sensitivity study and the aggregation-NAME modelling and wrote the first draft paper. ER designed the aggregation scheme as part of his PhD project, supervised by CB. FB and ER integrated the scheme into NAME. BD performed the scaling analysis. CB oversaw the analysis and instigated the project. CW supervised the project. All authors contributed to the finalization of

545 the paper

Competing interests. The authors declare that they have no conflict of interest.

Acknowledgements. This project has received funding from the European Union's Horizon 2020 research and innovation programme under grant agreement No 731070 (EUROVOLC). FB would like to thank Matthew Hort for his enthusiastic support and for reviewing a draft of this manuscript. 


\section{References}

Arastoopour, H., Wang, C. H., and Weil, S.: Particle-particle interaction force in a diluite gas-solid system., Chem. Eng. Sci., 37, 1379-1386, 1982.

Aubry, T., Carazzo, G., and Jellinek, A. M.: Turbulent entrainment into volcanic plumes: New constraints from laboratory experiments on buoyant jets rising in a stratified crossflow., Geophysical Research Letters, 44, https://doi.org/10.1002/2017GL075 069, 2017.

Bagheri, G., Rossi, E., Biass, S., and Bonadonna, C.: Timing and nature of volcanic particle clusters based on field and numerical investigations., JVGR, 327, 520-530, 2016.

Beckett, F., Witham, C., Hort, M., Stevenson, J., Bonadonna, C., and Millington, S.: Sensitivity of dispersion model forecasts of volcanic ash clouds to the physical characteristics of the particles., JGR: Atmospheres, 120, doi:10.1002/2015JD023 609, 2015.

Beckett, F., Witham, C., Leadbetter, S., Crocker, R., Webster, H., Hort, M.C. Jones, A., Devenish, B., and Thomson, D.: Atmospheric Dispersion Modelling at the London VAAC: A Review of Developments since the 2010 Eyjafjallajökull Volcano Ash Cloud., Atmosphere, 11:352, doi:10.3390/atmos11040352, 2020.

Bonadonna, C. and Phillips, J.: Sedimentation from strong volcanic plumes, Journal of Geophysical Research, 108, B00 $203,2003$.

Bonadonna, C., Macedonio, G., and Sparks, R.: Numerical modelling of tephra fallout associated with dome collapses and Vulcanian explosions: application to hazard assessment on Montserrat, in: The Eruption of Soufriere Hills Volcano, Montserrat, from 1995 to 1999. , edited by Druitt, T. and Kokelaar, B., pp. 517-537, Geological Society of London, 2002.

Bonadonna, C., Genco, R., Gouhier, M., Pistolesi, M., Cioni, R., Alfano, F., Hoskuldsson, A., and Ripepe, M.: Tephra sedimentation during the 2010 Eyjafjallajökull eruption (Iceland) from deposit, radar, and satellite observations, Journal of Geophysical Research, 116, B12 202, 2011.

Bonadonna, C., Biass, S., and Costa, A.: Physical characterization of explosive volcanic eruptions based on tephra deposits: propagation of uncertainties and sensitivity analysis., Journal of Volcanology and Geothermal Research, 296, 10.1016/j.jvolgeores.2015.03.009, 2015.

Brown, R., Bonadonna, C., and Durant, A.: A review of volcanic ash aggregation., Phys. Chem. Earth, 45-46, 65-78, 2012.

Carazzo, G. and Jellinek, A.: A new view of the dynamics, stability and longevity of volcanic clouds, Earth and Planetary Science Letters, 325-326, 39-51, 2012.

Carey, S. and Sigurdsson, H.: Influence of particle aggregation of deposition of distal tephra from the May 18, 1980, eruption of Mount St. Helens Volcano, Journal of Geophysical Research., 87, B8, 7061-7072, 1983.

Cashman, K. and Rust, A.: Far-travelled ash in past and future eruptions: combining tephrochronology with volcanic studies, Journal of Quaternary Science, 1-12, doi:10.1002/jqs.3159, 2019.

Cerminara, M., Espoti Ongaro, T., and Berselli, L.: ASHEE-1.0: a compressible, equilibrium-Eulerian model for volcanic ash plumes, Geosci. Model Dev., 9, 697-730, 2016a.

Cerminara, M., Ongaro, T., and Neri, A.: Large Eddy Simulation of gas-particle kinematic decoupling and turbulent entrainment in volcanic plumes, J. Volcanol. Geotherm. Res., 326, 143-171, 2016b.

Cornell, W., Carey, S., and Sigurdsson, H.: Computer-simulation of transport and deposition of the Campanian Y-5 ash, J. Volcanol. Geotherm. Res., 17, 89-109, 1983.

Costa, A., Folch, A., and Macedonio, G.: A model for wet aggregation of ash particles in volcanic plumes and clouds: 1. Theoretical formulation, JGR, 115, B09 201, 2010. 
Costa, A., Suzuki, Y. J., Cerminara, M., Devenish, B. J., Esposti Ongaro, T., and et al.: Results of the eruptive column model inter-comparison study, JVGR, 326, 2-25, 2016.

Dacre, H., Grant, A., Hogan, R., Belcher, S., Thomson, D., Devenish, B., Marenco, F., Hort, M., Haywood, J., Ansmann, A., Mattis, I., and Clarisse, L.: Evaluating the structure and magnitude of the ash plume during the initial phase of the 2010 Eyjafjallajökull eruption using lidar observations and NAME simulations. , Journal of Geophysical Research, 116, D00U03, 2011.

Del Bello, E., Taddeucci, J., Scarlato, P., Giacalone, E., and Cesaroni, C.: Experimental investigation of the aggregation-disaggregation of colliding volcanic ash particles in turbulent, low-humidity suspensions., Geophysical Research Letters, 42, 1068-1075, 2015.

Del Bello, E., Taddeucci, J., de’ Michieli Vitturi, M., Scarlato, P., Andronico, D., Scollo, S., Kueppers, U., and Ricci, T.: Effect of particle volume fraction on the settling velocity of volcanic ash particles: insights from joint experimental and numerical simulations., Scientific Reports, 6:39620, DOI: 10.1038/srep39 620, 2017.

Devenish, B.: Using simple plume models to refine the source mass flux of volcanic eruptions according to atmospheric conditions, JVGR, 326, 114-119, 2013.

Devenish, B.: Estimating the total mass emitted by the eruption of Eyjafjallajökull in 2010 using plume-rise models, JVGR, 256, 118-127, 2016.

600 Devenish, B., Francis, P., Johnson, B., Sparks, R., and Thomson, D.: Sensitivity analysis of dispersion modelling of volcanic ash from Eyjafjallajökull in May 2010., Journal of Geophysical Research, 117, D00U21, 2012a.

Devenish, B., Thomson, D., Marenco, F., Leadbetter, S., Ricketts, H., and Dacre, H.: A study of the arrival over the United Kingdom in April 2010 of the Eyjafjallajökull ash cloud using the ground-based lidar and numerical solutions, Atmsopheric Environment, 48, 152-164, $2012 b$.

Dioguardi, F., Beckett, F., Dürig, T., and Stevenson, J.: The impact of eruption source parameter uncertainties on ash dispersion forecasts during explosive volcanic eruptions, Journal of Geophysical Research: Atmospheres, doi 10.1029/2020JD032717, 2020.

Durant, A.: Toward a realistic formulation of fine-ash lifetime in volcanic, Geology, 43, 271-272, 2015.

Durant, A. and Rose, W.: Sedimentological constraints on hydrometeor-enhanced particle deposition: 1992 Eruptions of Crater Peak, Alaska, JVGR, 186, 40-59, 2009.

610 Durant, A., Shaw, R., Rose, W., Mi, Y., and Ernst, G.: Ice nucleation and overseeding of ice in volcanic clouds, JGR, 113, D09206, 2008.

Durant, A., Rose, W., Sarna-Wojcicki, A., Carey, S., and Volentik, A.: Hydrometeor-enhanced tephra sedimentation: Constraints from the 18 May 1980 eruption of Mount St. Helens, JGR, 114, B03 204, 2009.

Egan, S. D., Stuefer, M., Webley, P., Lopez, T., Cahill, C., and Hirtl, M.: Modeling volcanic ash aggregation processes and related impacts on the April/May 2010 eruptions of Eyjafjallajökull Volcano with WRF-Chem, Nat. Hazards Earth Syst. Sci. Discuss., https://doi.org/10.5194/nhess-2019-382, In Review, 2019.

Emanuel, K.: Atmospheric Convection, Oxford University Press, Oxford, 1994.

Eychenne, J., Cashman, J., Rust, A., and Durant, A.: Impact of the lateral blast on the spatial pattern and grain size characteristics of the 18 May 1980 Mount St. Helens fallout deposit., J. Geophys. Res. Solid Earth, 120, doi:10.1002/2015JB012 116, 2015.

Eychenne, J., Rust, A., Cashman, K., and Wobrock, W.: Distal enhanced sedimentation from volcanic plumes: Insights from the secondary mass maxima in the 1992 Mount Spurr fallout deposits., Journal of Geophysical Research: Solid Earth, 122, https://doi. org/10.1002/2017JB014 412, 2017.

Field, P., Heymsfield, A., and Bansemer, A.: A test of ice self-collection kernels using aircraft data., Journal of the Atmospheric Sciences, 9, 651-666, 2006. 
Folch, A., Costa, A., Durant, A., and Macedonio, G.: A model for wet aggregation of ash particles in volcanic plumes and clouds: 2. Model application., JGR., 115, B09202, doi:10.1029/2009JB007 176, 2010.

Folch, A., Costa, A., and Macedonio, G.: FPLUME-1.0: An integral volcanic plume model accounting for ash aggregation., Geosci. Model Dev., 63, 431-450, 2016.

Gabellini, P., Rossi, E., Bonadonna, C., Pistolesi, M., Bagheri, G., and Cioni, R.: Physical and Aerodynamic Characterization of Particle Clusters at Sakurajima Volcano (Japan), Front. Earth Sci., 8:575874, doi: 10.3389/feart.2020.575 874, 2020.

Gilbert, J. and Lane, S.: The origin of accretionary lapilli, Bull. Volc, 56, 398-411, 1994.

Gudnason, J., Thordarson, T., Houghton, B., and Larsen, G.: The opening subplinian phase of the Hekla 1991 eruption: Properties of the tephra fall deposit, Bull. Volc, 79, 34, 2017.

James, M., Gilbert, J., and Lane, S.: Experimental investigation of volcanic particle aggregation in the absence of a liquid phase., JGR., 107, B9, 2191, 2002.

James, M., Lane, S., and Gilbert, J.: Density, construction, and drag coeffcient of electrostatic volcanic ash aggregates., JGR., 108, B9, 2435, 2003.

Jones, A., Thomson, D., Hort, M., and Devenish, B.: The UK Met Office's next-generation atmospheric dispersion model, NAME III, in: Air Pollution Modelling and its Application, edited by Borrego, C. and Norman, A.-L., pp. 580-589, Springer, 2007.

Krumbein, W.: Size frequency distributions of sediments and the normal phi curve., Journal of Sedimentary Petrology, 8, 84-90, 1938.

Kumar, S. and Ramkrishna: On the solution of population balance equations by discretization .1. A fixed pivot technique.., Chem. Eng. Sci., 51, 1311-1332, 1996.

Lane, S., Gilbert, J., and Hilton, M.: The aerodynamic behaviour of volcanic aggregates., Bull. Volcanol., 55, 481-488, 1993.

Liu, L. and Litster, J.: Population balance modelling of granulation with a physically based coalescence kernel., Chemical Engineering Science, 57, 2183-2191, 2002.

Liu, L., Litster, J., Iveson, S., and Ennis, B.: Coalescence of Deformable Granules in Wet Granulation Processes., AIChE, 46, 3, 529-539, 2000.

Manzella, I., Bonadonna, C., Phillips, J., and Monnard, H.: The role of gravitational instabilities in deposition of volcanic ash, Geology, 43, 211-214, 2015.

Mastin, L.: Testing the accuracy of a 1-D volcanic plume model in estimating mass eruption rate, J. Geophys. Res. Atmos., 119, 474-2495, 2014.

Mastin, L., Schwaiger, H., Schneider, D., Wallace, K., Schaefer, J., and Denlinger, R.: Injection, transport, and deposition of tephra during event 5 at Redoubt Volcano, 23 March, 2009, JVGR, 259, 201-213, 2013.

Mastin, L., Van Eaton, A., and Durant, A.: Adjusting particle-size distributions to account for aggregation in tephra-deposit model forecasts., ACP, 16, 9399-9420, 2016.

Mueller, S., Kueppers, U., Ayrisa, P., Jacob, M., and Dingwell, D.: Experimental volcanic ash aggregation: Internal structuring of accretionary lapilli and the role of liquid bonding., Earth Planet. Sci. Lett., 433, 232-240, 2016.

Mueller, S., Kueppers, U., Ametsbilcher, J. Cimarelli, C., Merrison, J., Poret, M., Wadsworth, F., and Dingwell, D.: Stability of volcanic ash aggregates and break-up processes.., Sci. Rep., 7, 7440, 2017.

Murphy, D. and Koop, T.: Review of the vapour pressures of ice and supercooled water for atmospheric applications., Q. J. R. Meteorol. Soc., 131, 1539-1565, 2005. 
Osman, S., Beckett, F., Rust, A., and Snee, E.: Understanding grain size distributions and their impact on ash dispersal modelling., Atmosphere, 11, 567, 2020.

Pollastri, S., Rossi, E., Bonadonna, C., and J.P., M.: Effect of Electrification on Volcanic Ash Aggregation.., Front. Earth Sci, 8, 574 106, 2021.

Poret, M., Costa, A., Folch, A., and Martí, A.: Modelling tephra dispersal and ash aggregation: The 26th April 1979 eruption, La Soufrière St. Vincent, JVGR, 347, 207-220, 2017.

Poulidis, A. and Iguchi, M.: Model sensitivities in the case of high-resolution Eulerian simulations of local tephra transport and deposition, Atmospheric Research, 247, 105 136, 2020.

Poulidis, A., Takemi, T., Iguchi, M., and Renfrew, I.: Orographic effects on the transport and deposition of volcanic ash: A case study of Mt. Sakurajima, Japan, Journal of Geophysical Research: Atmospheres, 122, 9332-9350,, 2017.

Rose, W., Bluth, G., and Ernst, G.: Integrating retrievals of volcanic cloud characteristics from satellite remote sensors: a summary, Phil. Trans. Soc. Lond. A., 358, 1585-1606, 2000.

Rossi, E., Bagheri, G., Beckett, F., and Bonadonna, C.: The fate of volcanic ash aggregates: premature or delayed sedimentation?, Nature Communications, 12, 1303, 2021.

675 Scollo, S., Folch, A., and Costa, A.: A parametric and comparative study of different tephra fall out models, JVGR, 176, 199-211, 2008.

Smoluchowski, M.: Drei Vorträge über Diffusion, Brownsche Molekularbewegung und Koagulation von Kolloidteilchen., Physik. Z., 17, 557-585, 1916.

Stevenson, J., Millington, S., Beckett, F. M., Swindles, G., and Thordarson, T.: Understanding the discrepancy between tephrochronology and satellite infrared measurements of volcanic ash, Atmos. Meas. Tech., 8, 2069-2091, 2015.

Taddeucci, J., Scarlato, P., Montanaro, C., Cimarelli, C., Del Bello, E., Freda, C., Andronicao, D., Gudmundsson, M., and Dingwell, D.: Aggregation-dominated ash settling from the Eyjafjallajökull volcanic cloud illuminated by field and laboratory high-speed imaging., Geology, 39, 891-894, 2011.

Telling, J. and Dufek, J.: An experimental evaluation of ash aggregation in explosive volcanic eruptions, JVGR, 209-210, 1-8, 2012.

Telling, J., Dufek, J., and Shaikh, A.: Ash aggregation in explosive volcanic eruptions, Geophysical Research Letters, 40, 1-6, 2013.

Textor, C. and Ernst, G.: Comment on "Particle aggregation in volcanic eruption columns" by Graham Veitch and Andrew W. Woods., JGR, 109, B05 202, 2004.

Textor, C., Graf, H., Herzog, M., Oberhuber, J., Rose, W., and Ernst, G.: Volcanic particle aggregation in explosive eruption columns. Part I: Parameterization of the microphysics of hydrometeors and ash, JVGR, 150, 359-377, 2006a.

Textor, C., Graf, H., Herzog, M., Oberhuber, J., Rose, W., and Ernst, G.: Volcanic particle aggregation in explosive eruption columns. Part

II: Numerical experiments, JVGR, 150, 378-394, 2006b.

Veitch, G. and Woods, A.: Particle Aggregation in volcanic eruption columns., JGR, 106, B11, 26 425-26441, 2001.

Watt, S., Gilbert, J., Folch, A., Phillips, J., and Cai, X.: An example of enhanced tephra deposition driven by topographically induced atmospheric turbulence, Bull. Volc., 77, 35, 2015.

Webster, H., Thomson, D., Johnson, B., Heard, I., Turnbull, K., Marenco, F., Kristiansen, N., Dorsey, J., Minikin, A., Weinzierl, B., Schumann, U., Sparks, R., Loughlin, S., Hort, M., Leadbetter, S., Devenish, B., Manning, A., Witham, C., Haywood, J., and Golding, B.: Operational prediction of ash concentrations in the distal volcanic cloud from the 2010 Eyjafjallajökull eruption, Journal of Geophysical Research, 117, D00U08, 2012. 
https://doi.org/10.5194/acp-2021-254

Preprint. Discussion started: 31 May 2021

(c) Author(s) 2021. CC BY 4.0 License.

(c) (1)

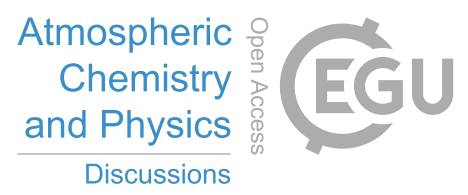

Woodhouse, M., Hogg, A., and Phillips, J.: A global sensitivity analysis of the PlumeRise model of volcanic plumes, Journal of Volcanology and Geothermal Research, 326, 54-76, 2016.

700 Woods, A.: The fluid dynamics and thermodynamics of eruption columns., Bulletin of Volcanology, 50, 169-193, 1988. 